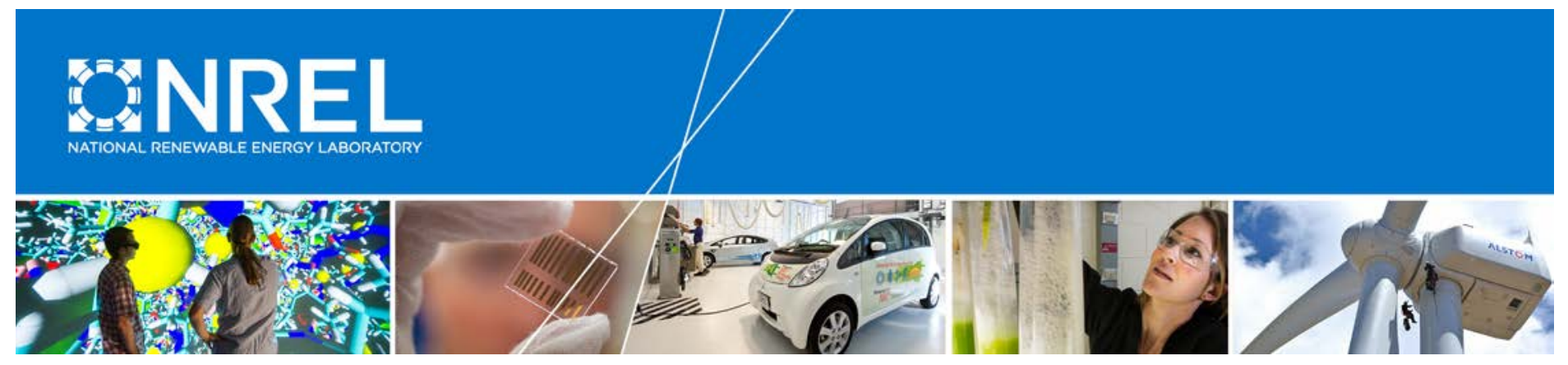

\title{
Solar Plus: A Holistic Approach to Distributed Solar PV
}

Eric O'Shaughnessy, Kristen Ardani, Dylan Cutler, and Robert Margolis National Renewable Energy Laboratory

NREL is a national laboratory of the U.S. Department of Energy Office of Energy Efficiency \& Renewable Energy Operated by the Alliance for Sustainable Energy, LLC

This report is available at no cost from the National Renewable Energy Laboratory (NREL) at www.nrel.gov/publications.

Technical Report

NREL/TP-6A20-68371

June 2017

Contract No. DE-AC36-08G028308 


\section{Solar Plus: A Holistic Approach to Distributed Solar PV}

\author{
Eric O'Shaughnessy, Kristen Ardani, \\ Dylan Cutler, and Robert Margolis \\ National Renewable Energy Laboratory
}

Prepared under Task No. ST6B.1452
National Renewable Energy Laboratory 15013 Denver West Parkway Golden, CO 80401

303-275-3000 • www.nrel.gov
NREL is a national laboratory of the U.S. Department of Energy Office of Energy Efficiency \& Renewable Energy Operated by the Alliance for Sustainable Energy, LLC

This report is available at no cost from the National Renewable Energy Laboratory (NREL) at www.nrel.gov/publications.

\section{Technical Report}

NREL/TP-6A20-68371

June 2017

Contract No. DE-AC36-08GO28308 


\section{NOTICE}

This report was prepared as an account of work sponsored by an agency of the United States government. Neither the United States government nor any agency thereof, nor any of their employees, makes any warranty, express or implied, or assumes any legal liability or responsibility for the accuracy, completeness, or usefulness of any information, apparatus, product, or process disclosed, or represents that its use would not infringe privately owned rights. Reference herein to any specific commercial product, process, or service by trade name, trademark, manufacturer, or otherwise does not necessarily constitute or imply its endorsement, recommendation, or favoring by the United States government or any agency thereof. The views and opinions of authors expressed herein do not necessarily state or reflect those of the United States government or any agency thereof.

This report is available at no cost from the National Renewable Energy Laboratory (NREL) at www.nrel.gov/publications.

Available electronically at SciTech Connect http:/www.osti.gov/scitech

Available for a processing fee to U.S. Department of Energy and its contractors, in paper, from:

U.S. Department of Energy

Office of Scientific and Technical Information

P.O. Box 62

Oak Ridge, TN 37831-0062

OSTI http://www.osti.gov

Phone: 865.576.8401

Fax: 865.576.5728

Email: reports@osti.gov

Available for sale to the public, in paper, from:

U.S. Department of Commerce

National Technical Information Service

5301 Shawnee Road

Alexandria, VA 22312

NTIS http://www.ntis.gov

Phone: 800.553 .6847 or 703.605 .6000

Fax: 703.605.6900

Email: orders@ntis.gov 


\section{Acknowledgments}

This work was supported by the Solar Energy Technologies Office at the U.S. Department of Energy (DOE). The authors would like to thank the following individuals and organizations for their thoughtful review of this work: Kate Anderson (NREL), Stina Brock (Sunverge Energy, Inc.), Dan Cross-Call (Rocky Mountain Institute), Mark Dyson (Rocky Mountain Institute), Charlie Gay (DOE), Sarah Kurtz (NREL), Karl Rábago (Pace Energy and Climate Center), Anthony Teixeira (Rocky Mountain Institute), and Brian Warshay (SolarCity). The authors would also like to thank Mike Meshek (NREL) and Jarett Zuboy (consultant) for editorial support. 


\section{List of Acronyms}

$\mathrm{AC}$

BEopt

BESS

DC

DHW

EWB

$\mathrm{kW}$

$\mathrm{kWh}$

Misc

NPV

NREL

ODB

PV

REopt

TMY3

TOU air conditioner

Building Energy Optimization model

battery energy storage load (system charging)

direct current

domestic hot water load

entering wet bulb temperature

kilowatt

kilowatt-hour

miscellaneous customer load (other than AC

and DHW)

net present value

National Renewable Energy Laboratory

outdoor dry bulb temperature

photovoltaic(s)

Renewable Energy Optimization model

typical meteorological year

time of use 


\section{Executive Summary}

"Solar plus" refers to an emerging approach to distributed solar photovoltaic (PV) deployment that uses energy storage and controllable devices to optimize customer economics. Solar plus increases customer system value through technologies such as electrical batteries, smart domestic water heaters, smart air conditioner (AC) units, and electric vehicles (Figure ES-1).

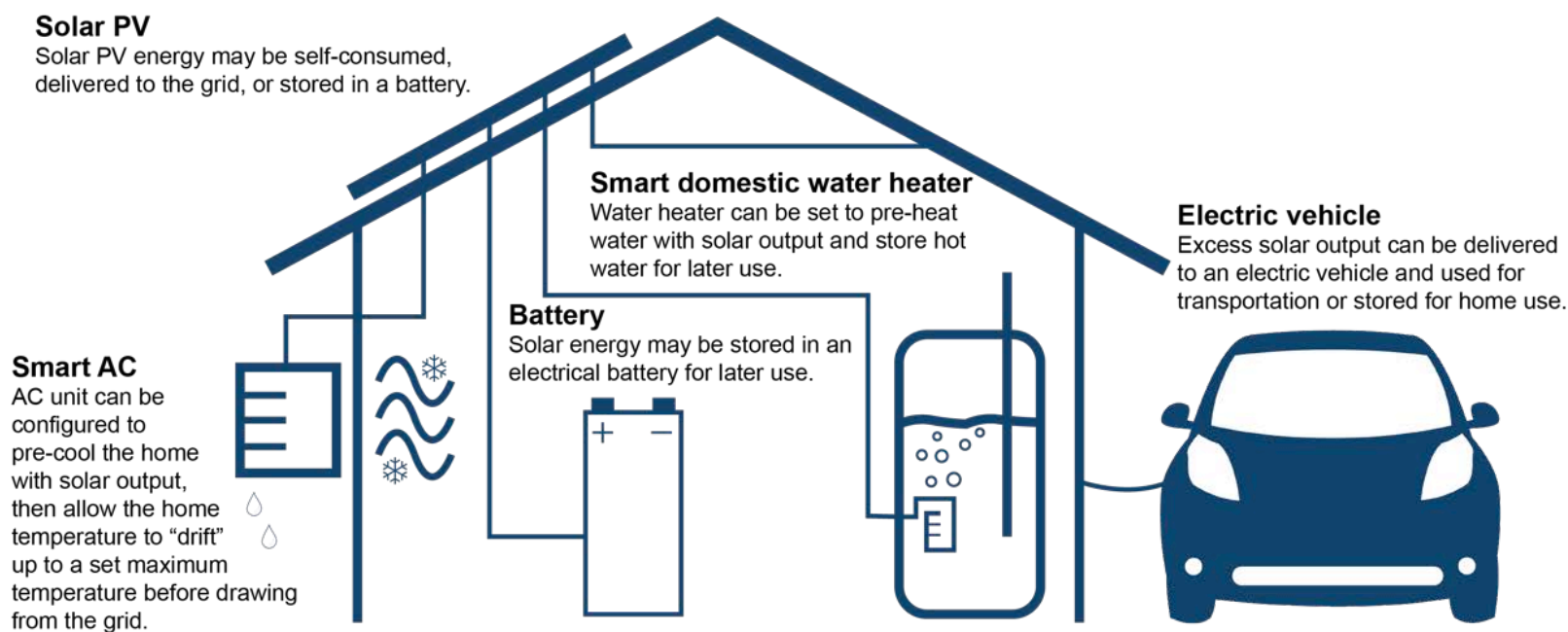

Figure ES-1. The solar plus approach

Currently, in U.S. locations where net metering exists, utilities compensate PV customers at or near the local retail rate for excess PV output delivered to the grid. However, recent trends toward lower net metering rates and other rate reforms could make PV less economically attractive to PV customers. Solar plus holds potential to mitigate some negative impacts of this evolving environment. Solar plus technologies shift certain customer loads "under" the PV production curve to maximize solar self-use and reduce grid electricity use (Figure ES-2). In areas where customers pay time-of-use (TOU) rates or demand charges, solar plus technologies provide additional benefits by shifting grid electricity use from high-cost periods to low-cost periods.

We use the National Renewable Energy Laboratory's Renewable Energy Optimization (REopt) model to explore the customer-side economics of solar plus under various utility rate structures and net metering rates. We also explore optimal solar plus applications in five case studies with different net metering rates and rate structures. REopt deploys different configurations of PV, batteries, smart domestic water heaters, and smart AC units in response to different rate structures and customer load profiles. Electric vehicles and other possible solar plus technologies are excluded from the analysis owing to data and modeling limitations.

Our analysis indicates that solar plus improves the customer economics of PV relative to standalone solar. REopt deploys at least one solar plus technology in addition to PV in all five case studies. Solar plus increases the net present value of the customer's total investment by a factor of about three, on average, across the five case studies. 

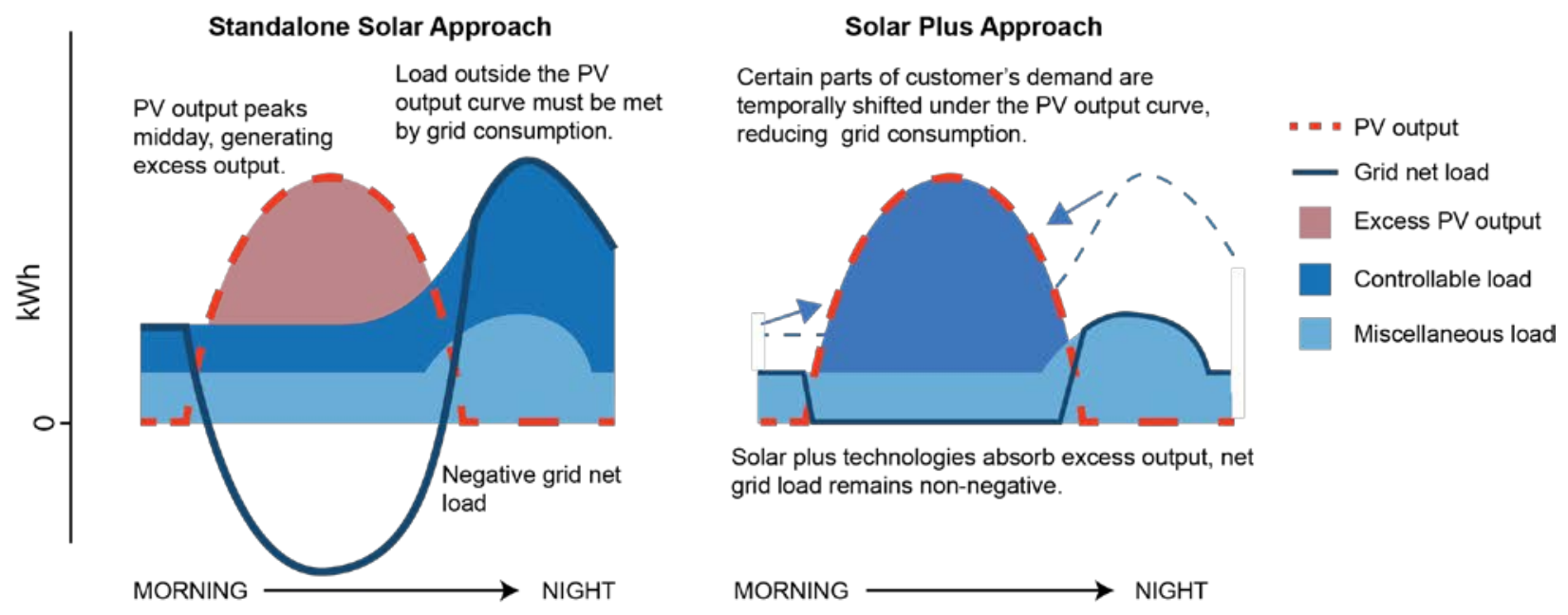

Figure ES-2. Customer load shifting through solar plus

Grid net load is the total customer load at the utility meter; negative grid net load reflects excess PV output exported to the grid.

The results of our analysis have four primary implications:

- Solar plus increases system value. Solar plus increases system value relative to a standalone solar approach in all five case studies. Higher system values derive from increased solar self-use and grid energy arbitrage.

- Solar plus generally affects the optimal PV system size. Solar plus results in more cost-effective PV system sizes when optimizing against current rate structures for customer savings. Solar plus PV systems may be larger or smaller than standalone solar PV systems, depending on rate structures and customer load profiles.

- Solar plus may mitigate some negative impacts of declining net metering rates and evolving rate structures on PV economics. The incremental value of solar plus, relative to standalone solar, is greatest for customers with low net metering rates and customers with TOU rates under which the peak rate period does not coincide with PV output.

- Current utility rate structures and battery costs generally do not support battery deployment based on customer bill savings alone. REopt only deploys batteries in two of the five case studies. However, batteries may be more economical when other value streams are considered (e.g., grid services and grid-outage resiliency) or if declining price trends continue.

In summary, our results indicate solar plus improves the customer economics of PV and may mitigate some of the negative impacts of evolving rate structures on PV economics. Solar plus may become an increasingly viable model for optimizing PV customer economics in an evolving rate environment. 


\section{Table of Contents}

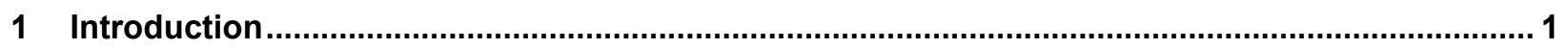

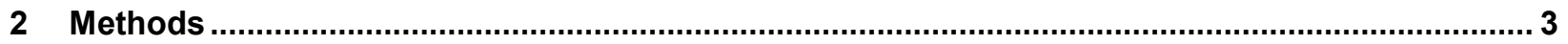

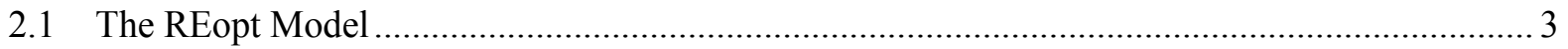

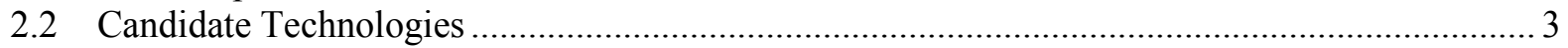

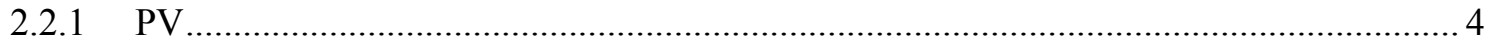

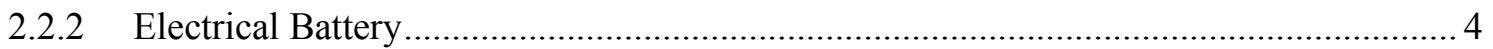

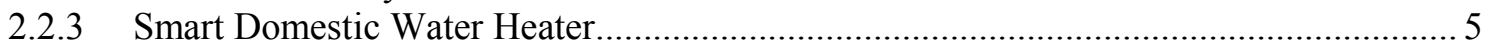

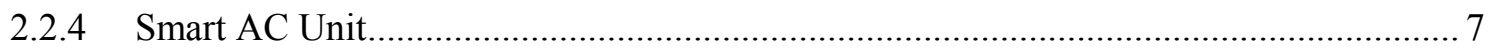

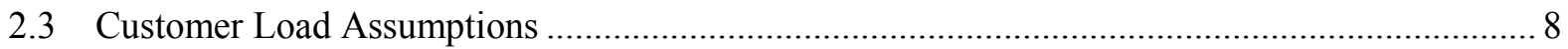

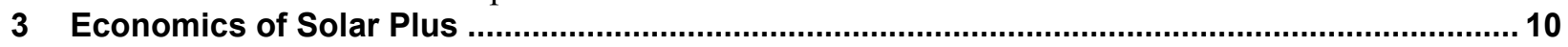

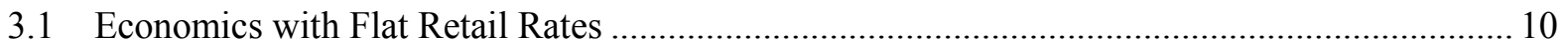

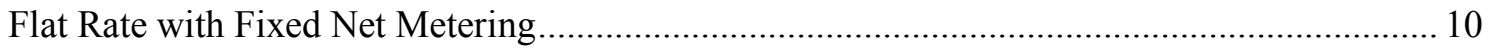

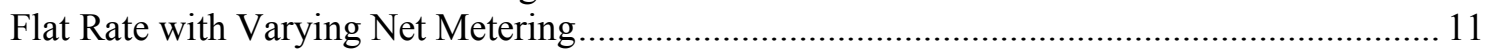

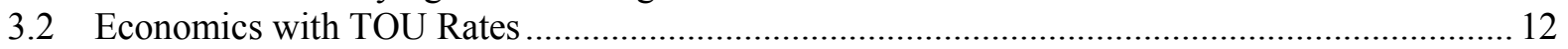

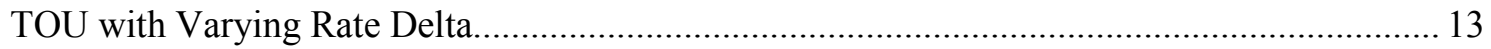

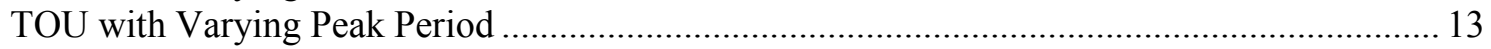

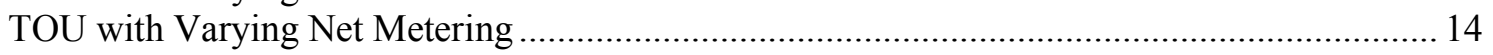

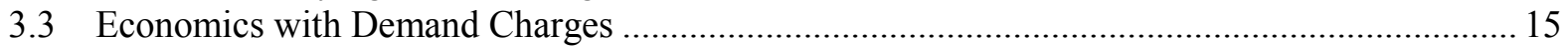

3.4 Summary: Effects of Rate Structure and Net Metering Rates on Solar Plus Economics............ 16

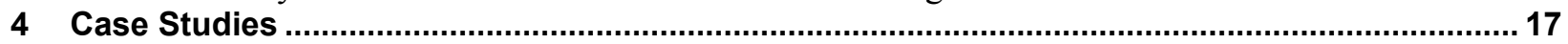

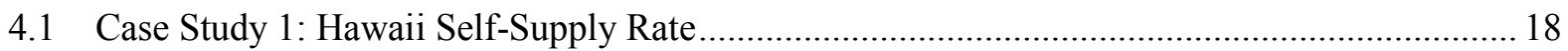

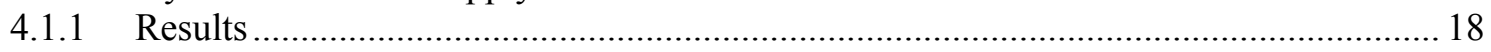

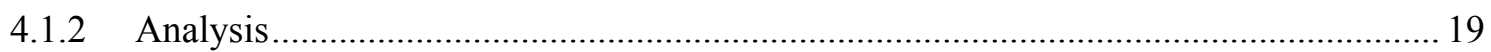

4.2 Case Study 2: Nevada Declining PV Export Rate............................................................ 21

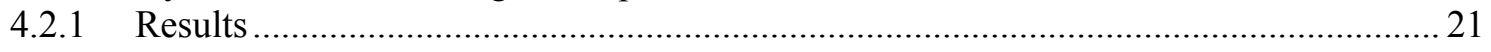

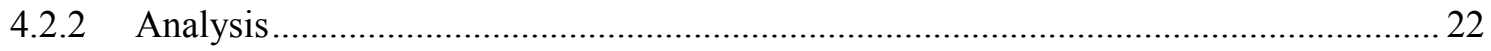

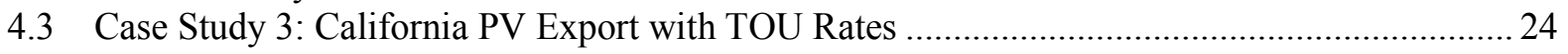

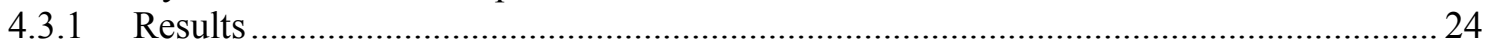

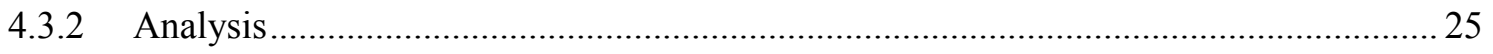

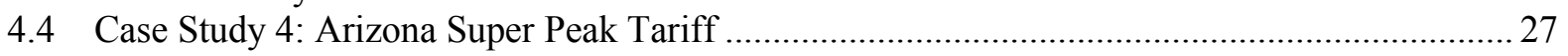

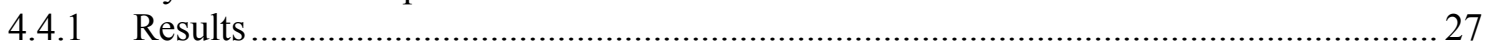

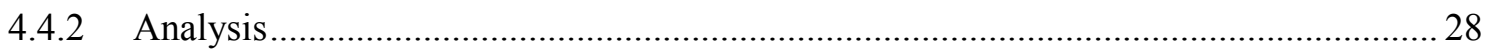

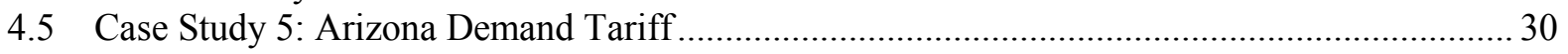

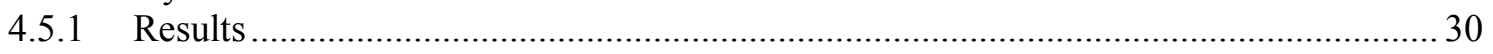

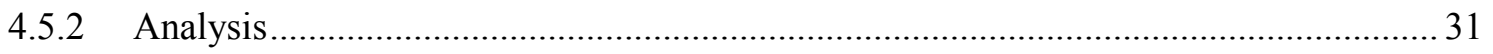

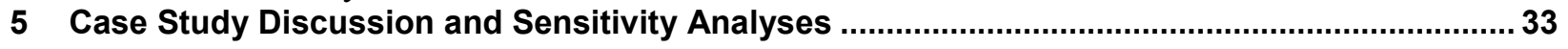

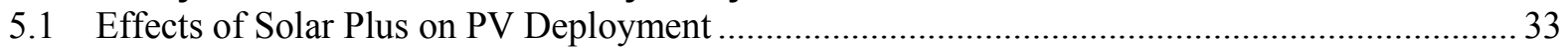

5.2 Deploying Low-Cost Modifications before High-Cost Batteries............................................. 34

5.3 Increasing System Value via Solar Plus........................................................................ 35

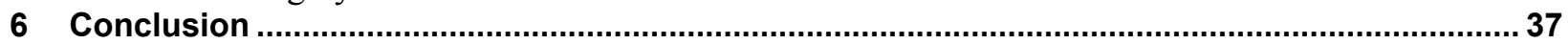

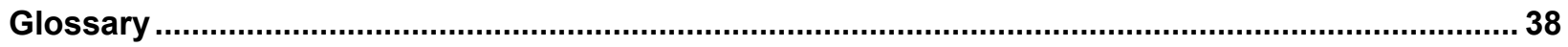

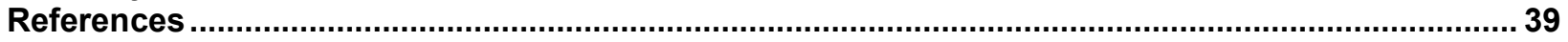




\section{List of Figures}

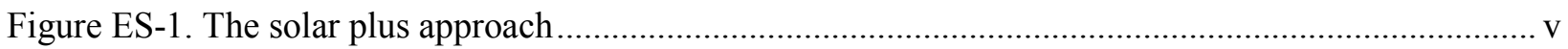

Figure ES-2. Customer load shifting through solar plus ....................................................................... vi

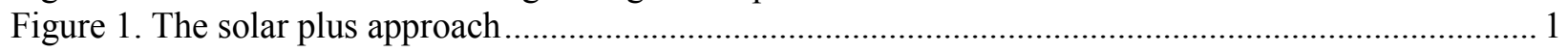

Figure 2. Customer load shifting through solar plus........................................................................... 2

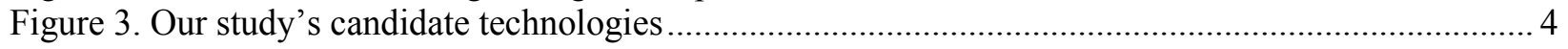

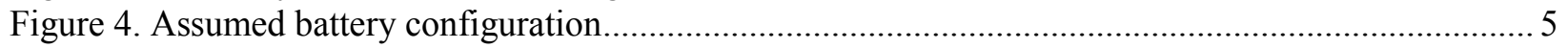

Figure 5. Conventional domestic water heating (top) vs. smart domestic water heating with preheating and

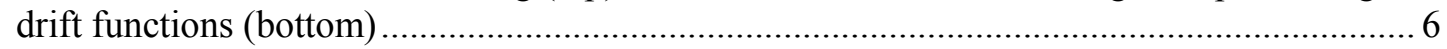

Figure 6. Conventional AC cooling (top) vs. smart AC with precooling and drift functions (bottom) ........ 7

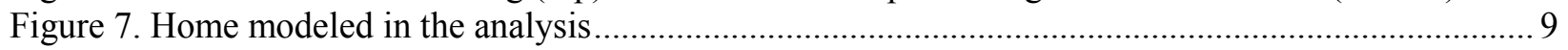

Figure 8. Solar plus economics under flat rates with fixed net metering ............................................. 11

Figure 9. Flat-rate solar plus economics under flat rate with varying net metering ................................ 12

Figure 10. Solar plus economics under different TOU rate deltas ........................................................ 13

Figure 11. Solar plus economics under different peak and off-peak periods.......................................... 14

Figure 12. Solar plus economics under different net metering rates with a TOU rate structure................. 15

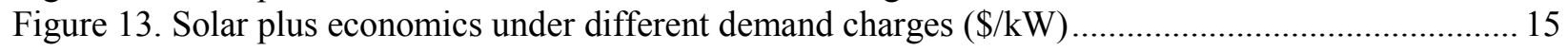

Figure 14. Hawaii case study PV and customer load profiles under standalone solar and solar plus

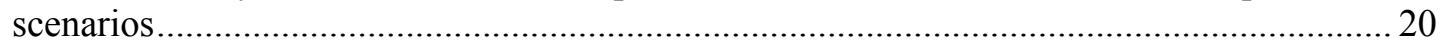

Figure 15. Nevada case study PV and customer load profiles under standalone solar and solar plus

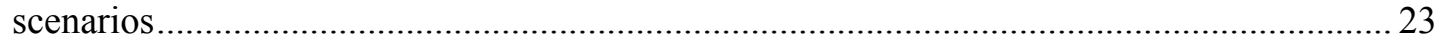

Figure 16. California case study PV and customer load profiles under standalone solar and solar plus

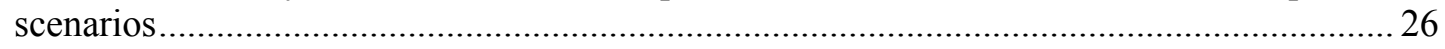

Figure 17. Arizona super peak case study PV and customer load profiles under standalone solar and solar

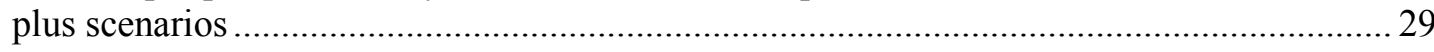

Figure 18. Arizona demand tariff case study PV and customer load profiles under standalone solar and

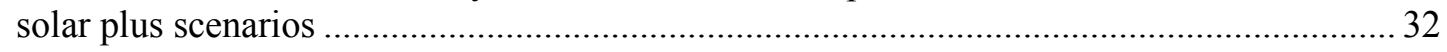

Figure 19. Optimal solar plus deployments across five case studies .............................................. 33

Figure 20. Optimal PV system sizes across case studies and approaches.............................................. 34

Figure 21. Sensitivity of battery deployment to battery costs in all case studies................................... 35

Figure 22. System NPV across case studies and approaches ............................................................. 36

\section{List of Tables}

Table 1. Flat Rate Sensitivity Analysis Scenarios and Assumptions ...................................................... 10

Table 2. TOU Sensitivity Analysis Scenarios and Assumptions .......................................................... 12

Table 3. Impacts of Rate Structure and Net Metering Parameters on PV System Values and Incremental

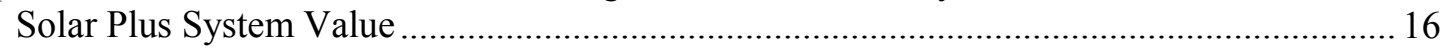

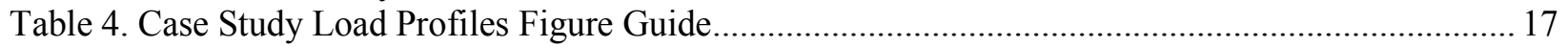

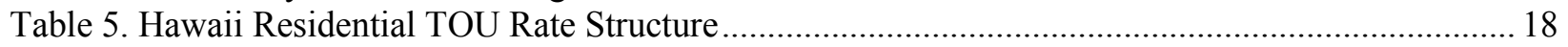

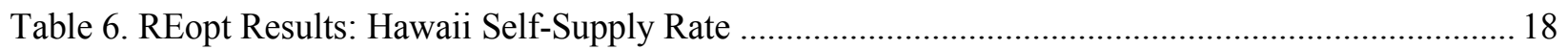

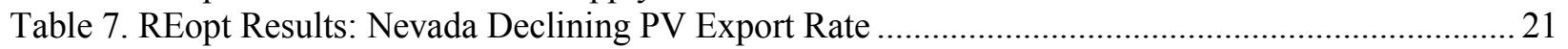

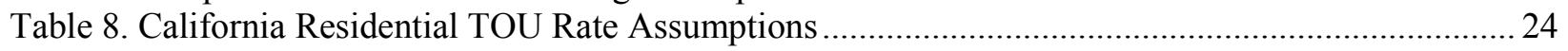

Table 9. REopt Results: California PV Export with TOU Rates ......................................................... 24

Table 10. Arizona Residential Super Peak Tariff Rate Structure ..................................................... 27

Table 11. REopt Results: Arizona Super Peak Tariff ..................................................................... 27

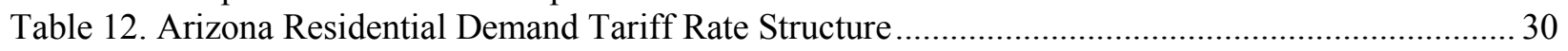

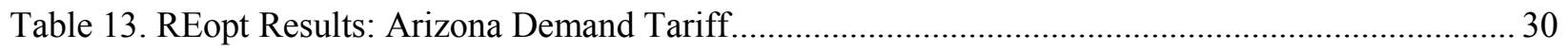




\section{Introduction}

The dependence of solar energy systems on diurnal sun cycles is one of the primary challenges to large-scale distributed solar photovoltaic (PV) deployment. PV output generally peaks with the midday sun and then subsides in the late afternoon as the sun sets. Electricity generated by the midday sun is no longer available to meet residential electricity demand in the late afternoon and evening. Energy storage, particularly battery storage, has emerged as one solution to the temporal mismatch of PV generation and customer load profiles. However, a growing body of literature and new PV product pairings indicate that "solar plus storage" is an overly narrow label to describe the next direction in the U.S. PV market. In this report, we explore the emerging potential of customer load control paired with energy storage to optimize the customer economics of residential PV systems. The intersection of PV, energy storage, and load control provides a holistic approach to PV deployment, which we call "solar plus."

Although many solar plus technologies are possible, this report focuses on four: PV, batteries, smart domestic water heaters, and smart air conditioner (AC) units (Figure 1). Electric vehicles are another potentially significant component of future solar plus systems, but we exclude them from our analysis owing to data and modeling limitations.

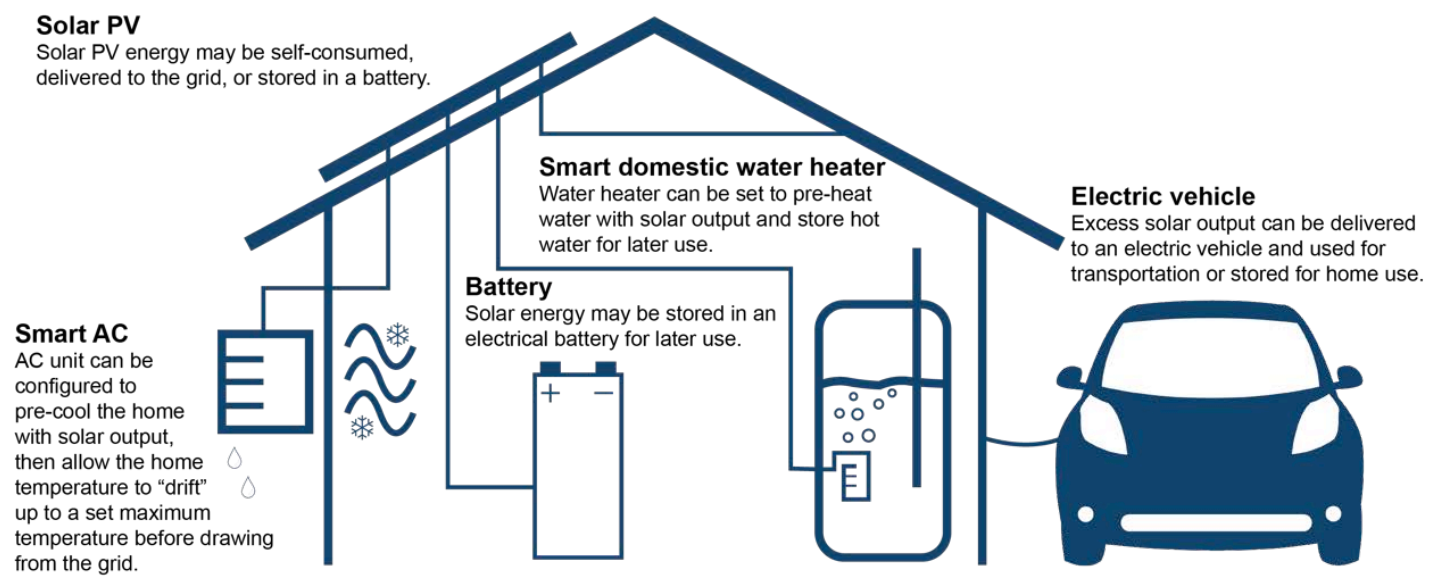

Figure 1. The solar plus approach

The elements in the figure depict one possible configuration. We do not analyze electric vehicles.

Depending on system size, some PV systems occasionally generate excess output (i.e., output greater than the customer's coincident load). Under the current net metering paradigm in the United States, some utilities credit excess output against PV customers' grid electricity use at or near the full retail rate. Net metering has bolstered the economics of distributed residential-scale PV in the United States by compensating customers for excess output. Net metering has been particularly valuable for customers who have higher retail rates during the day than at night.

However, recent state-level trends (e.g., in Hawaii and Nevada) suggest U.S. PV markets may need to adapt to an evolving rate environment. Lower net metering rates and some other rate reforms make PV less economically attractive to PV customers, but solar plus can mitigate some of the negative impacts of this environment. Solar plus technologies temporally shift some customer loads so they are "under" the PV production curve and able to absorb excess PV 
output (Figure 2). Any remaining excess output may be delivered to a battery, effectively shifting the time when the PV generation is consumed. Solar plus can increase PV self-use (i.e., increase the amount of PV electricity consumed onsite), reduce grid exports, and reduce customer electricity payments.
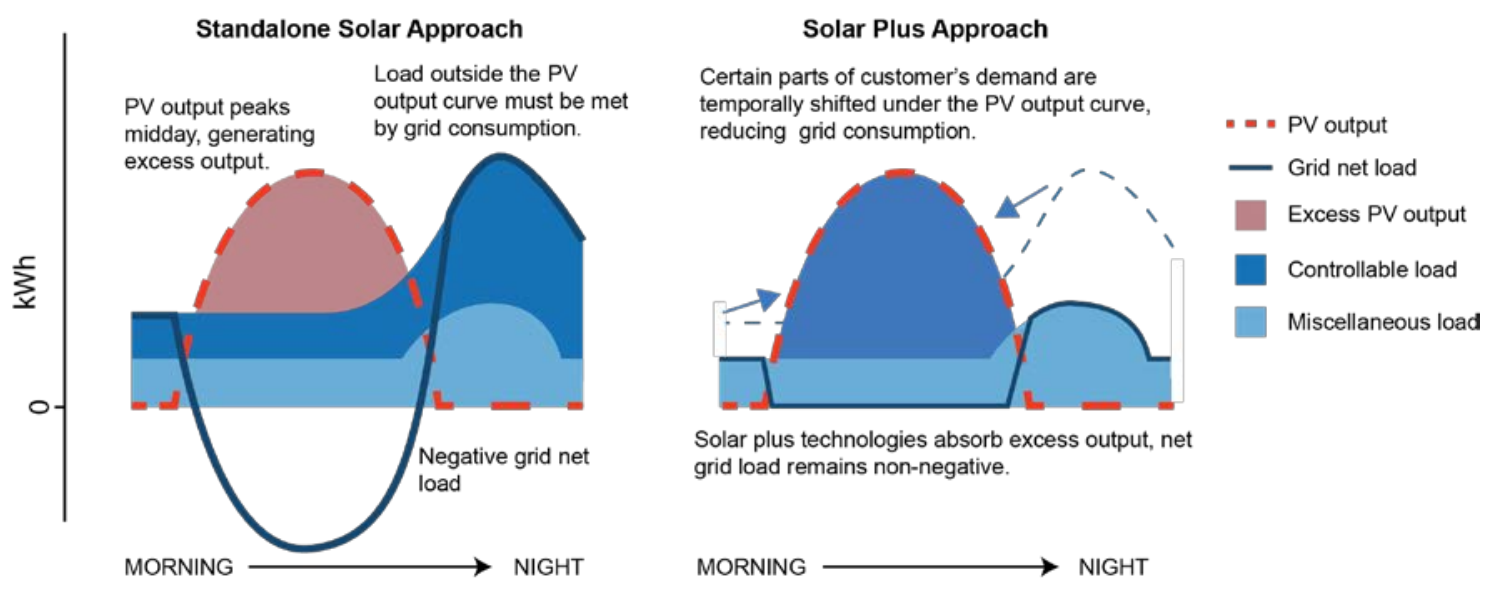

Figure 2. Customer load shifting through solar plus

Grid net load is the total customer load at the utility meter; negative grid load reflects excess PV output exported to the grid.

Several studies demonstrate how batteries and controllable devices can increase PV self-use (Castillo-Cagigal et al. 2011; Cao, Hasan, and Sirén 2013; Bronski et al. 2014; Luthander et al. 2015; Dyson et al. 2015; Parra, Walker, and Gillott 2016; Salpakari and Lund 2016; Braff, Mueller, and Trancik 2016; Fares and Webber 2017). In general, this literature indicates that the holistic solar plus approach improves the customer economics of PV. Several studies suggest the economics of solar plus depend on some gap between the customer's retail rate and the net metering rate (Khalilpour and Vassallo 2016; Salpakari and Lund 2016; Fares and Webber 2017). However, we demonstrate that this rule is not strict in situations with time-of-use (TOU) or demand-charge rate structures. Further, this rule need not apply if other value streams such as grid services are considered.

This report focuses exclusively on customer bill savings from the solar plus approach, but solar plus technologies can deliver a host of other grid-level benefits (Fitzgerald et al. 2015). Utilities and system operators may be able to aggregate solar plus technologies to provide ancillary services and use demand-side management to smooth customer load profiles. These additional benefits are areas for future research. Because we exclude these additional benefits from our analysis, we likely underestimate the full potential value of solar plus technologies.

We use an optimization model from the National Renewable Energy Laboratory (NREL) to study solar plus and its potential effects on distributed PV economics in an evolving rate environment. Section 2 outlines our methods. Section 3 examines the economics of solar plus under different rate structures and net metering rates. Section 4 presents the results of five case studies that explore the effects of rate structure and net metering rates on optimal solar plus systems based on actual utility rate structures. Section 5 discusses the implications of the results and provides sensitivity analyses. Section 6 concludes the report and suggests areas for future research. 


\section{Methods}

We analyze how different utility rate structures and net metering rates affect optimal solar plus systems using NREL's Renewable Energy Optimization (REopt) model. ${ }^{1}$ In our analysis, the constrained optimization problem is to maximize the net present value (NPV) of a customer's investment in PV and solar plus technologies subject to various utility rate structures, customer load profiles, technology capital and operating costs, and other technical and economic parameters. We use REopt to perform sensitivity analyses that build intuition around the economics of solar plus under different rate structures and net metering rates (Section 3 ). We then use it to analyze optimal solar plus systems for five case studies in four states: Hawaii, California, Nevada, and Arizona (Section 4).

\subsection{The REopt Model}

REopt is a techno-economic time-series model that provides concurrent, multiple technology integration and optimization capabilities. Formulated as a mixed-integer linear program, REopt identifies the optimal mix of candidate technologies and technology sizes, and it provides the dispatch strategy for operating these technologies at maximum economic efficiency.

The model's objective function is to minimize the present value of all energy costs over the analysis period, including capital costs of building new energy generation and storage capacity as well as operating expenses such as operations and maintenance costs and utility purchases. This analysis also accounts for the present value of incentives and depreciation. The model achieves an energy balance between demand and generation in every time step of the year across electric and thermal loads by sizing and dispatching a cost-optimal combination of renewable generation, conventional generation, and energy storage; we use hourly time steps for our analysis. The model also includes specific constraints that define how each technology can operate and which loads it can serve. REopt operates with perfect foresight of PV generation and customer load, so it models the maximum technical potential of all dispatchable technologies rather than empirically observed potential.

REopt leverages a number of NREL data sets for information on renewable energy resources, financial incentives, and technology capital and operating costs. The specific technologies modeled for this analysis and their relevant data sets are described in Section 2.2. For a full description of the model, refer to Simpkins et al. (2014).

\subsection{Candidate Technologies}

In our study, REopt chooses from among four candidate technologies: PV, an electrical battery, a smart domestic water heater, and a smart AC unit (Figure 3). REopt maximizes the return to the customer by selecting the optimal combination of candidate technologies under a given utility rate structure and then operating those technologies to minimize lifecycle customer electricity costs. Our analysis evaluates the decision to purchase technologies based purely on customer bill savings. Future analysis could integrate other benefits of solar plus technologies, such as gridoutage resiliency and ancillary services.

\footnotetext{
${ }^{1}$ See www.nrel.gov/tech_deployment/tools_reopt.html.
} 

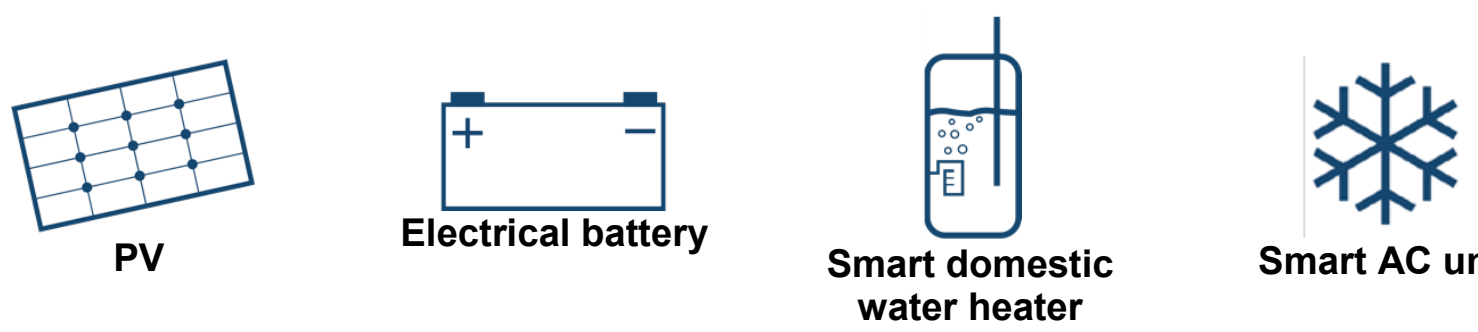

Smart AC unit

Figure 3. Our study's candidate technologies

Electric vehicles and other technologies could also be significant elements of solar plus systems. A typical electric vehicle has around $30 \mathrm{kWh}$ of electrical storage capacity, far greater than the capacity of current residential battery offerings. Electric vehicle owners could use this capacity for transportation or to temporally shift home electricity use. Our analysis excludes electric vehicles because electric vehicle ownership remains relatively uncommon. We aim to model the system of a representative PV customer without imposing assumptions about electric vehicle ownership.

\subsubsection{PV}

REopt estimates local PV production for each case study based on PVWatts ${ }^{\circledR}$, an NREL tool that estimates the energy production of grid-connected PV systems based on local insolation. ${ }^{2}$ The PVWatts model uses the same typical meteorological year (TMY3) file that is used in the building energy modeling, ensuring alignment between climatic impacts on the home and PV output. We assume a fixed-tilt PV system mounted at the angle of the roof (8:12 pitch), southfacing panels (azimuth of $180^{\circ}$ ), and with total system efficiency losses of $12 \%$. The maximum $\mathrm{PV}$ capacity is set to $8 \mathrm{~kW}$ based on the PV-suitable roof space on the modeled home. ${ }^{3}$ The PV system is assumed to cost $\$ 2.78 / \mathrm{W}$ before incentives, with a fixed operating cost of $\$ 20 / \mathrm{kW} /$ year (Ardani et al. 2017).

\subsubsection{Electrical Battery}

In REopt, PV-generated electricity can be stored in a battery for later use. The rate at which energy can be delivered to and from the battery depends on the inverter/rectifier capacity, as sized by the model. ${ }^{4}$ There are also inverter losses and roundtrip efficiency losses as energy moves in and out of the battery. Figure 4 shows the assumed battery configuration, with the battery coupled on the alternating current side of the system ${ }^{5}$ and two inverters: a grid-tied PV inverter (changing direct to alternating current) and a bi-directional battery-based inverter.

\footnotetext{
${ }^{2}$ See pvwatts.nrel.gov.

${ }^{3}$ Based on an installed capacity of $118 \mathrm{~W} / \mathrm{m}^{2}$ and $68 \mathrm{~m}^{2}$ of available roof area (out of $\sim 147 \mathrm{~m}^{2}$ of total roof area) ${ }^{4} \mathrm{PV}$ generates direct current (DC) electricity. An inverter is used to convert the DC into alternating current for home use. A rectifier is used to convert alternating current back to DC in certain configurations to store electricity in a battery.

${ }^{5}$ This configuration is called an alternating current-coupled system. DC-coupled systems are an alternative option in which the battery is coupled directly to the PV array on the DC side. See Ardani et al. (2017) for a more complete description of DC- and alternating current-coupled systems.
} 


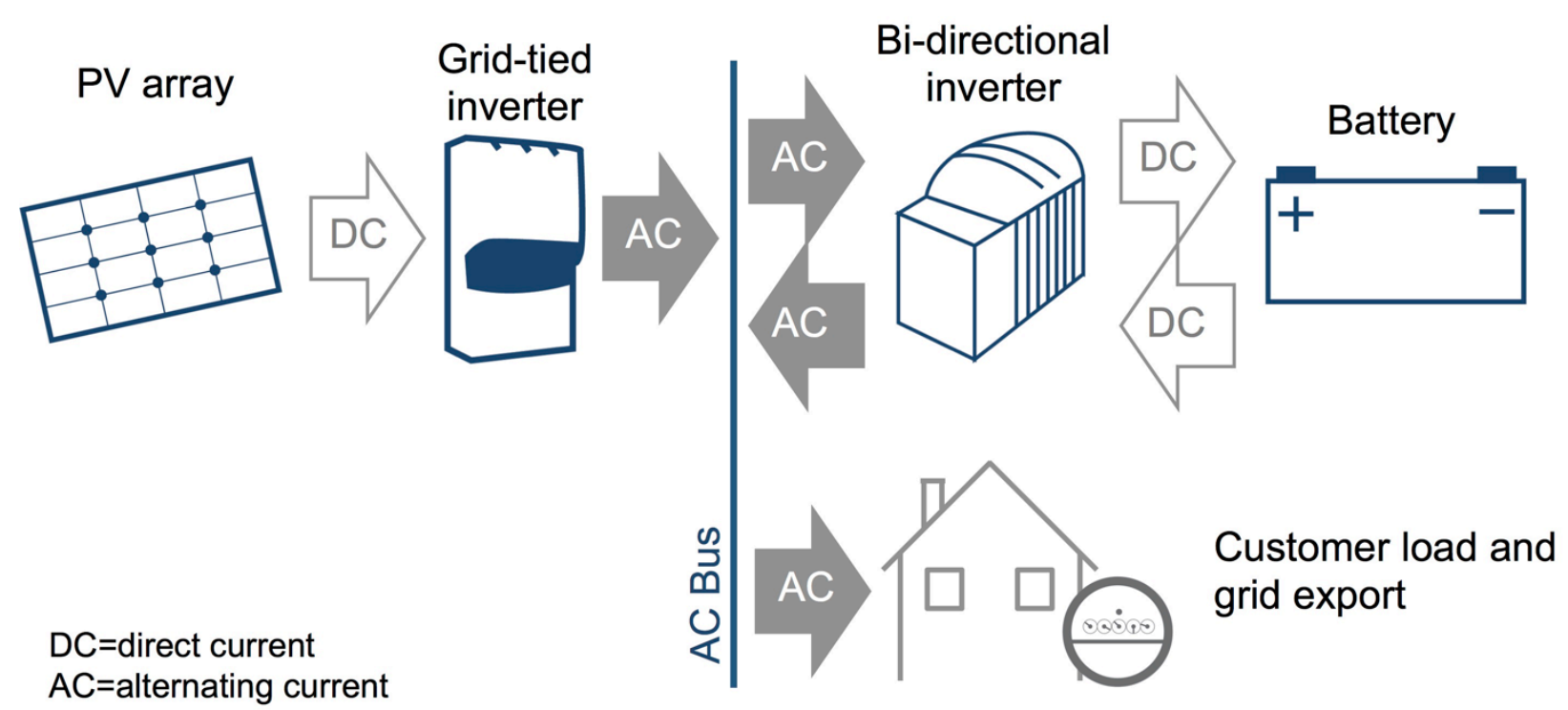

Figure 4. Assumed battery configuration

Most current PV-coupled batteries use lithium-ion technology, although other chemistries, such as lead-acid, are available. The parameters in this analysis are based on a lithium-ion battery. A minimum battery state of charge of $20 \%$ is assumed, meaning that $80 \%$ of the battery nameplate capacity is usable.

Modeled battery costs are based on benchmarked costs from Ardani et al. (2017). The battery pack is assumed to cost $\$ 1,060 / \mathrm{kWh}$, and the power electronics and remaining equipment (wiring, controls, etc.) are assumed to cost $\$ 1,271 / \mathrm{kW}$-alternating current, both before incentives. The battery capacity $(\mathrm{kWh})$ and inverter $(\mathrm{kW})$ sizes are optimized independently to minimize utility costs. Battery degradation is assumed to be determined primarily by shelf life (not cycling degradation). Batteries are replaced after 10 years (in year 11). Battery costs are assumed to decline at a rate of 6\%/year (Manghani 2014).

\subsubsection{Smart Domestic Water Heater}

The modeled home has a 50-gallon smart electric domestic water heater with a $4.5-\mathrm{kW}$ electric element. ${ }^{6}$ A conventional electric domestic water heater heats water immediately following hot water draws to maintain a set tank temperature (Figure 5, top). Equipped with an upgrade, the smart domestic water heater only heats water under certain conditions. It can preheat water to $180^{\circ} \mathrm{F}$ using PV output and then allow the tank temperature to "drift" down to $120^{\circ} \mathrm{F}$ without drawing from the grid to reheat the water (Figure 5, bottom). ${ }^{7}$ The tank volume and maximum allowed temperature determine the domestic water heater's energy storage capacity. The assumed tank size (50 gallons) and temperature range $\left(120^{\circ}-180^{\circ} \mathrm{F}\right)$ equate to $7.3 \mathrm{kWh}$ of thermal energy storage when the tank is fully heated.

\footnotetext{
${ }^{6}$ About $40 \%$ of U.S. homes use an electric water heater (DOE 2009).

${ }^{7}$ We assume the smart-heater upgrade includes a mixing valve to avoid scalding due to elevated tank temperatures as well as controls to enable heating to the desired tank temperature.
} 

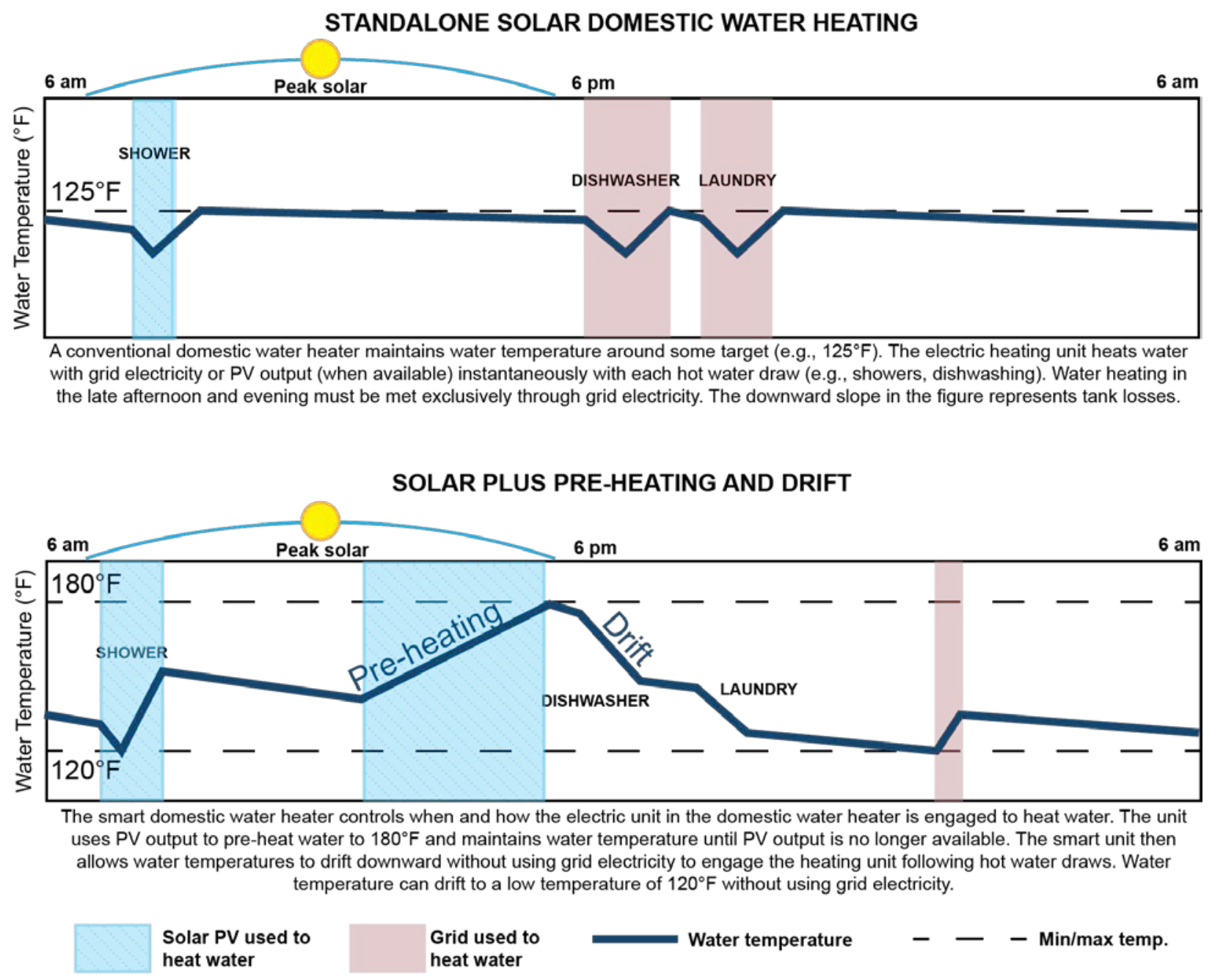

Figure 5. Conventional domestic water heating (top) vs. smart domestic water heating with

All domestic water heater tanks lose heat in between water draws, depicted in Figure 5 as a negative slope in water temperature in between hot-water events. Tank heat losses are a function of the overall heat-loss coefficient of the system, the average tank temperature, and the temperature of the ambient air. To model the tank losses in REopt's mixed-integer linear model, these losses are converted to a percentage of capacity lost per hour. Given an assumed heat-loss coefficient of $0.916 \mathrm{~W} / \mathrm{m}^{2}-{ }^{\circ} \mathrm{C}$ (Burch and Erikson 2004) and an indoor temperature of $70^{\circ} \mathrm{F}$, this value ranges from $1.44 \%$ /hour at $180^{\circ} \mathrm{F}$ to $2.76 \%$ /hour at $140^{\circ} \mathrm{F} .{ }^{8}$ For this analysis, a fixed value of $2 \%$ /hour is assumed.

The smart water heater upgrade costs $\$ 225$, based on an assumed incremental installed cost of \$200 for smart controls (Dyson et al. 2015) and an additional \$25 for a mixing valve to prevent scalding from increased temperatures.

\footnotetext{
${ }^{8}$ The higher percent-per-hour value at low temperature is due to the low total stored energy at that temperature.
} 


\subsubsection{Smart AC Unit}

Conventional AC units maintain a home's internal temperature around some target, such as $70^{\circ} \mathrm{F}$ (Figure 6, top). A smart AC unit includes a device added to the home's thermostat that controls when and how the home is cooled. We assume the smart AC upgrade allows an increased deadband $\left(66^{\circ}-74^{\circ} \mathrm{F}\right)$, the temperature range maintained by the $\mathrm{AC}$. This enables the system to use the home's thermal storage capacity by precooling to a minimum temperature of $66^{\circ} \mathrm{F}$ and allowing temperatures to drift up toward $74^{\circ} \mathrm{F}$. The $\mathrm{AC}$ unit remains off, hence reducing grid electricity use, until the home temperature exceeds $74^{\circ} \mathrm{F}$ (Figure 6 , bottom). The drift duration is a function of the thermal resistance-capacitance of the home and the ambient conditions. A home's thermal resistance-capacitance, effectively its ability to transfer and retain heat, is in turn a function of construction materials. For this analysis, the house constructions are based on the Building America benchmark design (see Section 2.3 for details). The local climate further dictates the drift period. For example, it may take several hours to drift from $66^{\circ} \mathrm{F}$ to $74^{\circ} \mathrm{F}$ if the outdoor air temperature is $80^{\circ} \mathrm{F}$, but the same drift may occur in under an hour if the outdoor air temperature is well above $90^{\circ} \mathrm{F}$ with high incident solar radiation. These climatic impacts are accounted for in the model by using TMY3 data to both determine hourly loads and hourly AC efficiency/capacity.

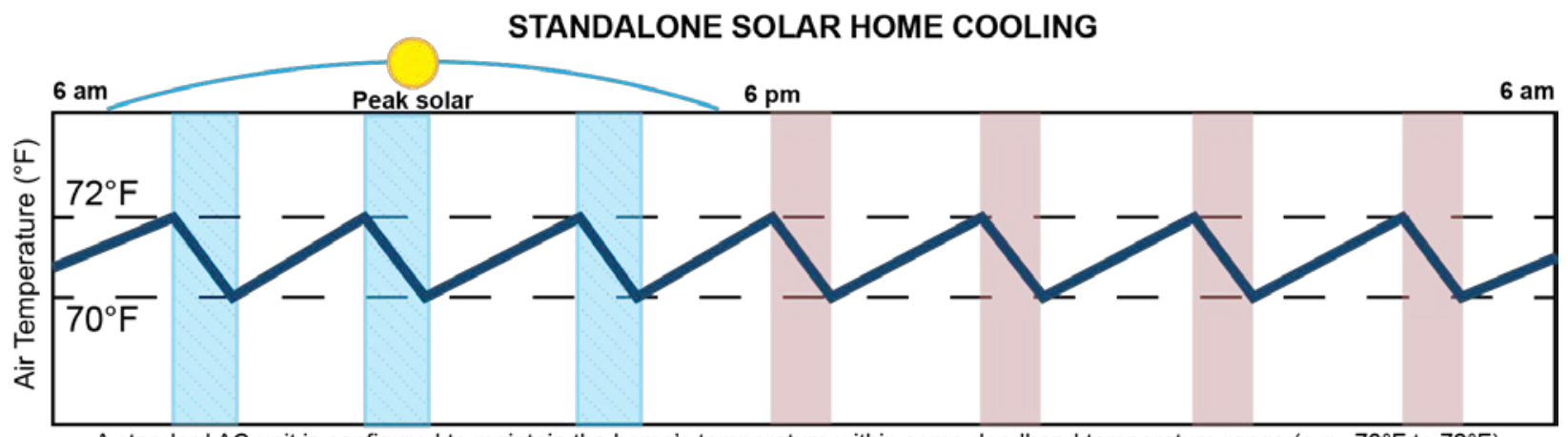

A standard AC unit is configured to maintain the home's temperature within some deadband temperature range (e.g., $70^{\circ} \mathrm{F}$ to $72^{\circ} \mathrm{F}$ ). Whenever the upper limit of the deadband is reached, the AC unit uses either grid electricity or PV output (when available) to cool the home to the lower limit of the deadband. Home temperatures in the late afternoon and evening are maintained using exclusively grid electricity when solar PV output is no longer available.

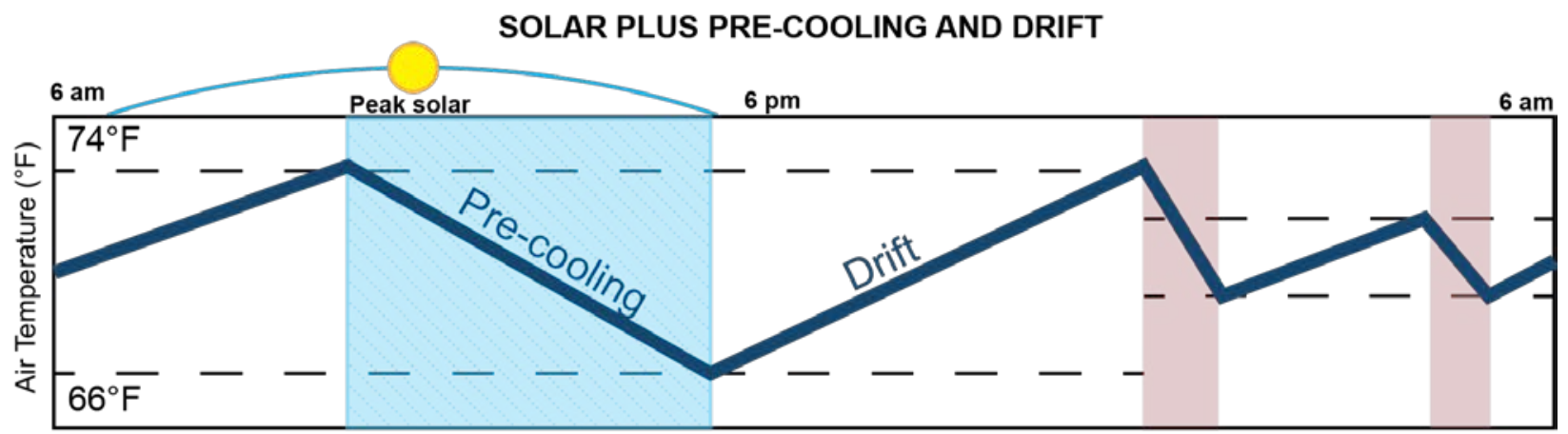

The smart $A C$ unit controls when and how the $A C$ unit maintains temperatures within an expanded deadband $\left(66^{\circ} \mathrm{F}\right.$ to $\left.74^{\circ} \mathrm{F}\right)$. The smart $\mathrm{AC}$ unit pre-cools the home using PV output and maintains internal temperature at $66^{\circ} \mathrm{F}$ until PV output is no longer available. The unit then allows temperatures to drift up to $74^{\circ} \mathrm{F}$ without using grid electricity to activate the cooling mechanism.

Solar PV used to power AC
Grid used to power AC
Home temperature

- - - Deadband

Figure 6. Conventional AC cooling (top) vs. smart AC with precooling and drift functions (bottom) 
We use a resistance-capacitance model to quantify the energy required to lower the house temperature from $74^{\circ} \mathrm{F}$ down to $66^{\circ} \mathrm{F}$, and to estimate the drift duration from $66^{\circ} \mathrm{F}$ up to $74^{\circ} \mathrm{F}$ (Mathieu, Dyson, and Callaway 2015). Both calculations (energy consumed in "on" mode and drift time in "off" mode) depend on outdoor air temperature. To isolate the home's thermal storage capacity, we calculate the energy required to move from $74^{\circ} \mathrm{F}$ to $66^{\circ} \mathrm{F}$ when the outdoor air temperature is at $70^{\circ} \mathrm{F}$. This removes any external loads on the system (because the outdoor temperature is within the deadband) and quantifies how much thermal energy can be put into the home. The total thermal storage capacity of the modeled home is calculated at $14 \mathrm{kWh}$-thermal.

To evaluate the resistance-capacitance model calculation described above, we enter a fixed thermostat schedule into the Building Energy Optimization tool (BEopt) to force the set point to $66^{\circ} \mathrm{F}$ during the morning and evening hours and $74^{\circ} \mathrm{F}$ during other hours of the day. After running the model with this set point schedule, we calculate the hours it takes to drive the system across the deadband as well as how many hours the house could drift with the AC system turned off. The calculated drift and required "on" time compare well with the results from the resistance-capacitance model.

We use performance curves that define AC capacity and efficiency based on outdoor dry bulb temperature (ODB) and entering wet bulb temperature (EWB) to model AC unit performance. This is a standard performance-based modeling approach that is employed in the whole-building simulation engines EnergyPlus and DOE 2.2. For this analysis, only the ODB/EWB performance curves are used, not the flow fraction and partial load curves that are included in the full EnergyPlus AC model. ${ }^{9}$ It should be noted that this model of the AC performance is implemented in the REopt model to enable the model to optimally dispatch that system while taking into account capacity and efficiency impacts of ambient conditions. This is separate from the cooling loads, which are modeled in BEopt (see section 2.3 below) and fed into the REopt model.

The smart AC unit entails an incremental installed cost of \$200 (Dyson et al. 2015).

\subsection{Customer Load Assumptions}

The modeled home size reflects national median values for single-family detached homes in the U.S. Energy Information Administration's Residential Energy Consumption Survey database. This results in a 199- $\mathrm{m}^{2}$ house with 3 bedrooms, 2 bathrooms, and 1.5 stories (Figure 7). We assume the house conforms to the Building America benchmark design as defined in Wilson and Horowitz (2016). This is generally consistent with the International Energy Conservation Code from 2009, the most widely used energy code for new construction in the United States.

\footnotetext{
${ }^{9}$ This is because REopt does not include a whole-building model that could calculate flow fraction or partial load on a time-step by time-step basis (whereas outdoor temperature is included in the TMY3 files, and indoor temperature is assumed to be a constant $70^{\circ} \mathrm{F}$ ). We use this simplification knowing that the ODB/EWB curves have the most significant impact on AC capacity and performance. The curves used for the AC model in REopt are from Cutler et al. (2013), and the rated efficiency and system capacity are from the output of the BEopt model for the given case study.
} 


\section{$199 \mathrm{~m}^{2}$ \\ 3 bedrooms \\ 2 bathrooms \\ 1.5 stories}

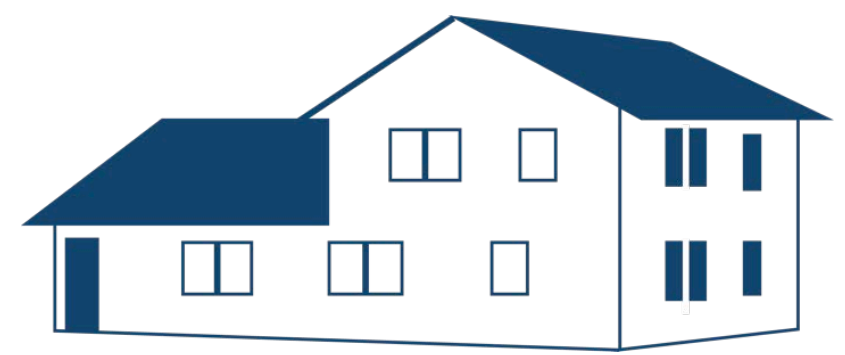

Figure 7. Home modeled in the analysis

Customer loads are modeled using NREL's BEopt model, with climatic conditions based on TMY3 data. The EnergyPlus simulation engine is used to model load profiles in the geographic locations of each case study based on the BEopt output. The home's energy demands are broken into three distinct categories: AC load, domestic hot water load, and miscellaneous electrical load (all loads not pertaining to AC or hot water). The disaggregation of loads allows REopt to dispatch the smart $\mathrm{AC}$ or domestic water heater to meet the thermal loads while shifting the electrical demand to different periods within the day, as enabled by the thermal storage of the domestic water heater or the home. The domestic water heater load in BEopt is based on the domestic hot water event schedule generator (Hendron, Burch, and Barker 2010), and the AC load and remaining electrical demand are calculated by the EnergyPlus simulation engine based on the defined building characteristics, occupancy/appliance schedules, and climatic conditions (as defined by the TMY3 weather files). 


\section{Economics of Solar Plus}

The economics of solar plus depend on the incremental values provided by solar plus technologies relative to a standalone solar system. This section provides the results of six REopt sensitivity analyses to build intuition around the economics of solar plus under different rate structures and net metering rates. In each analysis, we allow a single rate parameter to vary while holding all other factors constant. This approach allows us to isolate the effects of different parameters on the economics of solar plus. We compare outcomes with a standalone solar approach for which REopt cannot deploy solar plus technologies.

All analyses in this section use a customer load profile based on a home in Las Vegas. System NPVs are calculated relative to what the customer would pay without any PV system. A discount rate of $6.2 \%$ is assumed. Our rate assumptions reflect realistic ranges of parameters and are roughly consistent with the case studies developed in Section 4.

\subsection{Economics with Flat Retail Rates}

Most residential customers in the United States pay flat volumetric $(\$ / \mathrm{kWh})$ retail rates. To test the economics of solar plus under different flat rates, we explore two sensitivities: (1) we assume the net metering rate is fixed at $50 \%$ of the retail rate while we vary the retail rate from $\$ 0.10 / \mathrm{kWh}$ to $\$ 0.30 / \mathrm{kWh}$ and (2) we assume the retail rate is fixed at $\$ 0.22 / \mathrm{kWh}$ while we vary the net metering rate from $\$ 0.02 / \mathrm{kWh}$ to $\$ 0.22 / \mathrm{kWh}$ (Table 1).

Table 1. Flat Rate Sensitivity Analysis Scenarios and Assumptions

\begin{tabular}{|c|c|c|}
\hline Scenario & Assumptions & Basis \\
\hline \multirow{2}{*}{$\begin{array}{l}\text { Flat rate with fixed net } \\
\text { metering }\end{array}$} & $\begin{array}{l}\text { Flat rate varies from } \$ 0.10 / / \mathrm{kWh} \\
\text { to } \$ 0.30 / \mathrm{kWh} \text {. }\end{array}$ & $\begin{array}{l}\text { U.S. state-level average residential rates } \\
\text { range from } \$ 0.09 / \mathrm{kWh} \text { to } \$ 0.29 / \mathrm{kWh} \\
\text { (EIA 2017). }\end{array}$ \\
\hline & $\begin{array}{l}\text { Net metering is } 50 \% \text { of flat rate } \\
\text { at all rates. }\end{array}$ & $\begin{array}{l}\text { Represents net metering as proposed or } \\
\text { implemented by various state reforms. } \\
\text { For instance, Nevada's net metering rate } \\
\text { falls to about half of retail by } 2022 \text {. }\end{array}$ \\
\hline \multirow{2}{*}{$\begin{array}{l}\text { Flat rate with varying net } \\
\text { metering }\end{array}$} & Flat rate is $\$ 0.22 / \mathrm{kWh}$. & $\begin{array}{l}\text { Based on average rate from three major } \\
\text { PV markets: California, Hawaii, and New } \\
\text { England (EIA 2017). }\end{array}$ \\
\hline & $\begin{array}{l}\text { Net metering varies from } \$ 0.02 \\
\text { to } \$ 0.22 / \mathrm{kWh} \text {. }\end{array}$ & Illustrative range \\
\hline
\end{tabular}

\section{Flat Rate with Fixed Net Metering}

Here we vary the modeled customer's retail rate from $\$ 0.10 / \mathrm{kWh}$ to $\$ 0.30 / \mathrm{kWh}$ while holding net metering constant at $50 \%$ of the retail rate. REopt deploys the smart domestic water heater and smart $\mathrm{AC}$ unit at every retail rate, but it does not deploy a battery at any retail rate under these assumptions. 
Figure 8 plots the results of this sensitivity analysis. All customers with higher flat rates save more money per unit of PV output than do customers with lower flat rates, because the value of both solar self-use increases when the flat rate increases. As a result, system value increases under increasing flat rates for both standalone solar and solar plus. The incremental benefit of solar plus also increases with increasing flat rates - that is, PV customers with higher retail rates accrue more value from solar plus technologies than do customers with lower retail rates. This is because the value of the increased solar self-use made possible by solar plus technologies is higher when the absolute difference between the retail and net metering rates is larger. Compared with the standalone solar approach, the solar plus approach results in a larger optimal PV system size at a retail rate of $\$ 0.10 / \mathrm{kWh}$. Beyond $\$ 0.10 / \mathrm{kWh}$, REopt deploys the maximum system size $(8 \mathrm{~kW})$ under both approaches.

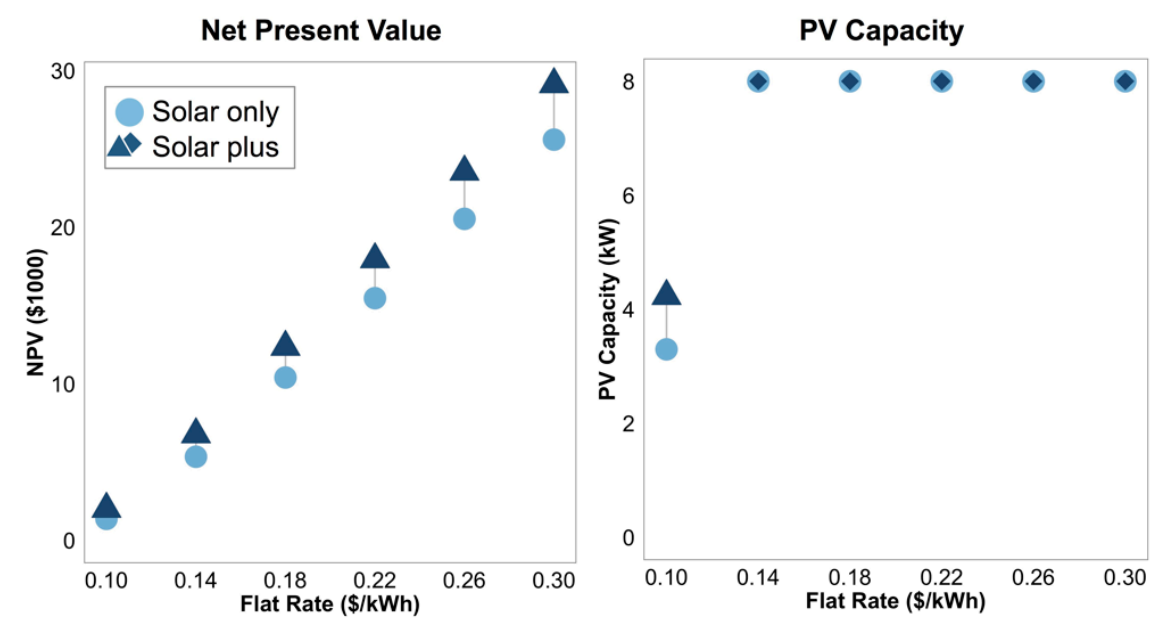

Figure 8. Solar plus economics under flat rates with fixed net metering

Figure assumes net metering is half of retail rate at every flat rate

\section{Flat Rate with Varying Net Metering}

Here we allow the net metering rate to vary from $\$ 0.02 / \mathrm{kWh}$ to $\$ 0.22 / \mathrm{kWh}$ while assuming a fixed flat retail rate of $\$ 0.22 / \mathrm{kWh}$. REopt deploys the smart domestic water heater and smart AC unit at every net metering rate, but it does not deploy a battery.

Figure 9 illustrates the results of this sensitivity analysis. System values and PV capacities for both the standalone solar and solar plus approaches increase with an increasing net metering rate. The incremental value of solar plus is higher at lower net metering rates. In other words, PV customers with low net metering rates accrue more incremental value from solar plus technologies, again because a larger absolute difference between the retail and net metering rates increases the value of the enhanced PV self-use made possible by solar plus technologies. The incremental value of solar plus becomes small as the net metering rate approaches the full retail rate. Compared with the standalone solar approach, solar plus results in a larger PV system size for net metering rates below $\$ 0.07 / \mathrm{kWh}$. At $\$ 0.07 / \mathrm{kWh}$ and above, REopt deploys the maximum system size $(8 \mathrm{~kW})$ under both approaches. 

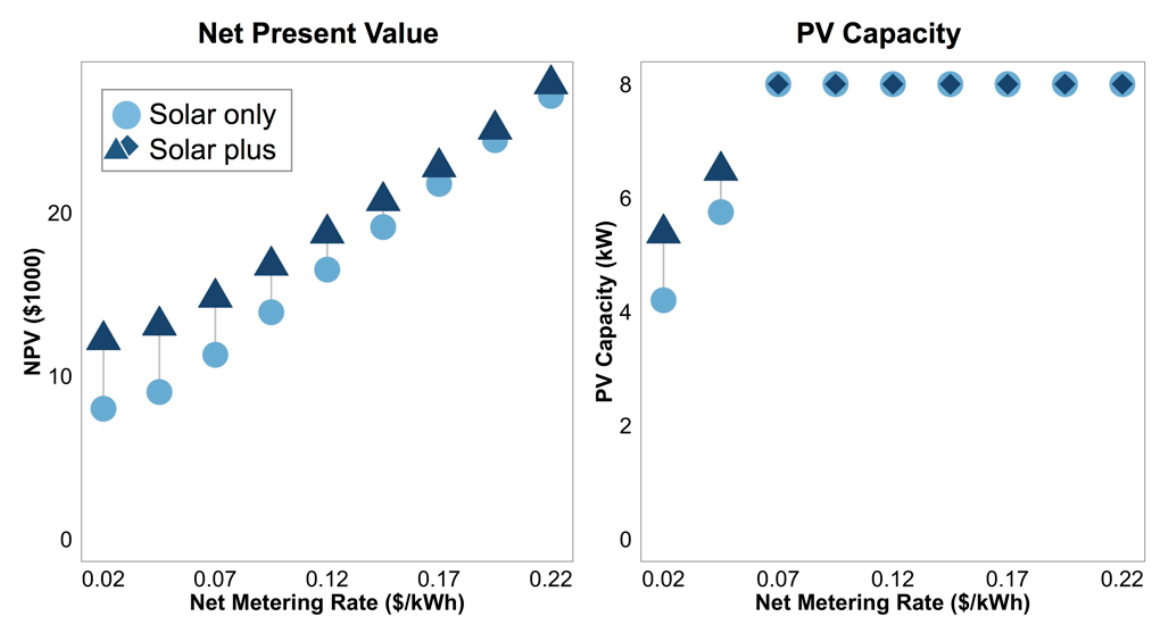

Figure 9. Flat-rate solar plus economics under flat rate with varying net metering

Figure assumes a flat volumetric electricity rate of $\$ 0.22 / \mathrm{kWh}$

\subsection{Economics with TOU Rates}

Some PV customers pay TOU rates, including those in some major PV markets such as California and Hawaii. TOU rate structures vary in two basic ways: (1) by the difference between peak and off-peak rates or the "rate delta" and (2) by the timing of the peak and offpeak periods. We explore the sensitivity of solar plus economics to changes in these two factors. We also examine the impacts of different net metering rates under a TOU structure (Table 2).

Table 2. TOU Sensitivity Analysis Scenarios and Assumptions

\begin{tabular}{|c|c|c|}
\hline Scenario & Assumptions & Basis \\
\hline \multirow[t]{2}{*}{$\begin{array}{l}\text { TOU with varying rate } \\
\text { delta }\end{array}$} & $\begin{array}{l}\text { Peak rate ranges from } \$ 0.14 \text { to } \\
\$ 0.42 / \mathrm{kWh} \text {. Off-peak rate is } \\
\$ 0.08 / \mathrm{kWh} \text {. Peak period is } 4-9 \\
\text { p.m. }\end{array}$ & $\begin{array}{l}{ }^{*} T O U: \text { In the TOU case studies in } \\
\text { Section } 4 \text {, off-peak rates range from } \\
\$ 0.06 / \mathrm{kWh} \text { to } \$ 0.22 / \mathrm{kWh} \text {, and peak rates } \\
\text { range from } \$ 0.20 / \mathrm{kWh} \text { to } \$ 0.47 / \mathrm{kWh} \text {. } \\
\text { Peak period is based on California's } \\
\text { TOU structure. }\end{array}$ \\
\hline & Net metering rate is $\$ 0.03 / \mathrm{kWh}$. & Based on Arizona TOU case study \\
\hline \multirow[t]{2}{*}{$\begin{array}{l}\text { TOU with varying peak } \\
\text { period }\end{array}$} & $\begin{array}{l}\text { Five-hour peak period starting } \\
\text { hours range from } 9 \text { a.m. to } \\
5 \text { p.m. Off-peak rate is } \\
\$ 0.08 / \mathrm{kWh} \text {. Peak rate is } \\
\$ 0.22 / \mathrm{kWh} \text {. }\end{array}$ & See *TOU \\
\hline & Net metering rate is $\$ 0.03 / \mathrm{kWh}$. & Based on Arizona TOU case study \\
\hline \multirow{2}{*}{$\begin{array}{l}\text { TOU with varying net } \\
\text { metering }\end{array}$} & $\begin{array}{l}\text { Off-peak rate is } \$ 0.08 / \mathrm{kWh} \text {. } \\
\text { Peak rate is } \$ 0.22 / \mathrm{kWh} \text {. Peak } \\
\text { period is } 4-9 \text { p.m. }\end{array}$ & See *TOU \\
\hline & $\begin{array}{l}\text { Net metering rate varies from } \\
\$ 0.02 / \mathrm{kWh} \text { to } \$ 0.22 / \mathrm{kWh} \text {. }\end{array}$ & Illustrative range \\
\hline
\end{tabular}




\section{TOU with Varying Rate Delta}

To model how rate deltas affect solar plus economics, we allow the peak rate to vary from $\$ 0.14 / \mathrm{kWh}$ to $\$ 0.42 / \mathrm{kWh}$, while holding the off-peak rate constant at $\$ 0.08 / \mathrm{kWh}$. This results in a rate delta of $\$ 0.06-\$ 0.34 / \mathrm{kWh}$. We assume a peak period of 4-9 p.m. and a net metering rate of $\$ 0.03 / \mathrm{kWh}$. REopt deploys the smart domestic water heater and smart AC unit at every rate delta, and it deploys relatively small batteries for rate deltas greater than $\$ 0.26 / \mathrm{kWh}$.

Figure 10 illustrates the results of the rate delta analysis. System values increase with increasing rate deltas under both approaches. However, because TOU customers with solar plus derive value from both increased solar self-use and grid arbitrage - shifting customer load from a high to a low rate period - and standalone solar customers do not, solar plus has a larger incremental value at larger rate deltas. Solar plus also results in a larger optimal PV system size at every rate delta.
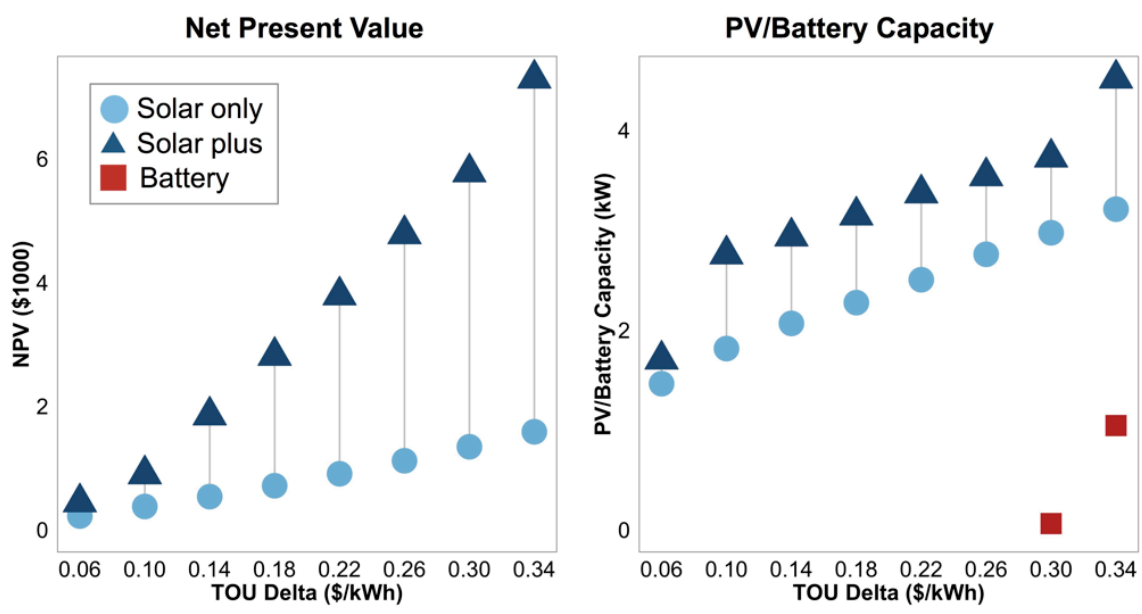

Figure 10. Solar plus economics under different TOU rate deltas

Figure assumptions: Off-peak rate is $\$ 0.08 / \mathrm{kWh}$. Peak period is $4-9$ p.m. Net metering rate is $\$ 0.03 / \mathrm{kWh}$

\section{TOU with Varying Peak Period}

Here we model solar plus under a range of 5 -hour peak periods, with each period starting at a different time on the hour from 9 a.m. to 5 p.m. For instance, in Figure 11, the point at 9 a.m. corresponds to a peak period of 9 a.m. -2 p.m., the point at 10 a.m. corresponds to a peak period of 10 a.m. -3 p.m., and so forth. We assume an off-peak rate of $\$ 0.08 / \mathrm{kWh}$, a peak rate of $\$ 0.22 / \mathrm{kWh}$, and a net metering rate of $\$ 0.03 / \mathrm{kWh}$. REopt deploys the smart domestic water heater and smart AC unit for each period, but it does not deploy a battery for any period.

Figure 11 presents the results of the peak-period timing analysis. Coincident PV self-use is more valuable when PV output coincides with the peak rate period. As a result, standalone solar system values are higher for midday peak periods and lower for late-afternoon peak periods. Solar plus system values show a similar pattern, but they remain relatively higher even for lateafternoon, non-coincident peak rate periods. Through increased solar self-use and grid arbitrage, solar plus technologies more effectively reduce late-afternoon peak rate grid electricity use than standalone solar does. Hence, PV customers with non-coincident, late-afternoon peak rates benefit more from solar plus than do PV customers with coincident midday peak rate periods. 
Figure 11 also shows how the timing of the TOU peak period affects optimal PV system sizes. For coincident peak periods, PV system size is smaller for solar plus than for standalone solar (see the Arizona case studies, Sections 4.4 and 4.5). For non-coincident peak periods, the solar plus approach results in a larger PV system size (see the Hawaii case study, Section 4.1). We explore this result in further depth in the case studies. In general, solar plus results in a more cost-effective PV system size, which may be larger or smaller than a standalone solar PV system depending on rate structure.
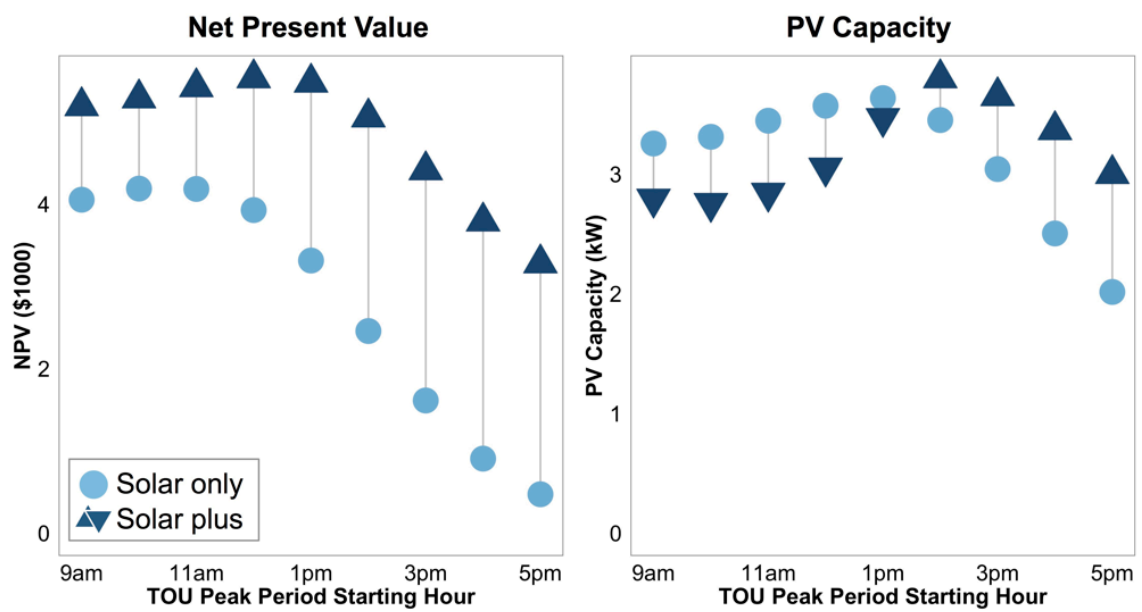

Figure 11. Solar plus economics under different peak and off-peak periods

Figure assumptions: Off-peak rate is $\$ 0.08 / \mathrm{kWh}$. Peak rate is $\$ 0.22 / \mathrm{kWh}$. Net metering rate is $\$ 0.03 / \mathrm{kWh}$

\section{TOU with Varying Net Metering}

Here we vary the net metering rate from $\$ 0.02 / \mathrm{kWh}$ to $\$ 0.22 / \mathrm{kWh}$ while holding the peak rate constant at $\$ 0.22 / \mathrm{kWh}$ and the off-peak rate constant at $\$ 0.08 / \mathrm{kWh}$. The peak period is $4-9$ p.m. REopt deploys the smart domestic water heater and smart AC unit at each net metering rate, but it does not deploy a battery at any rate.

Figure 12 shows the results of the net metering analysis. Solar plus system values are higher than standalone solar system values at every net metering rate. The incremental value of solar plus with TOU rates is slightly higher at lower net metering rates. Compared with the standalone solar approach, the solar plus approach results in a larger optimal PV system size at net metering rates below $\$ 0.07 / \mathrm{kWh}$. At $\$ 0.07 / \mathrm{kWh}$ and above, REopt deploys the maximum system size $(8 \mathrm{~kW})$ under both approaches. 

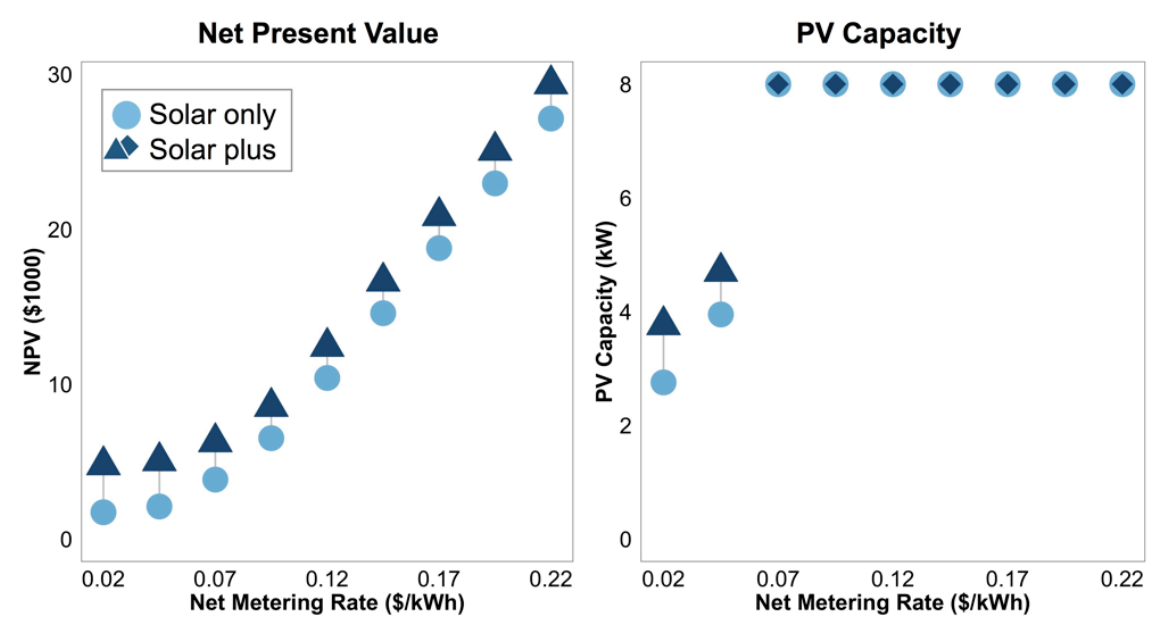

Figure 12. Solar plus economics under different net metering rates with a TOU rate structure

Figure assumptions: Off-peak rate is $\$ 0.08 / \mathrm{kWh}$; peak rate is $\$ 0.22 / \mathrm{kWh}$, peak period is $4-9$ p.m.

\subsection{Economics with Demand Charges}

Demand charges affect solar plus economics under flat rates, although residential demand charges are uncommon. Here we assume demand charges of $\$ 14 / \mathrm{kW}$ to $\$ 28 / \mathrm{kW}$ while holding constant a flat rate of $\$ 0.06 / \mathrm{kWh}$ and a net metering rate of $\$ 0.03 / \mathrm{kWh}$.

Figure 13 illustrates solar plus economics under different demand charges. REopt does not deploy a PV system in the standalone solar scenario, and the standalone system value is zero at every demand charge. The solar plus approach provides system value at every demand charge from grid arbitrage and reshaping the customer's demand profile. In the solar plus scenario, REopt deploys a PV system at demand charges of $\$ 20 / \mathrm{kW}$ and above, and it deploys a battery for demand charges of $\$ 18 / \mathrm{kW}$ and above. Small PV system sizes are consistent with findings that demand charges result in smaller optimal PV system sizes (Darghouth et al. 2017).
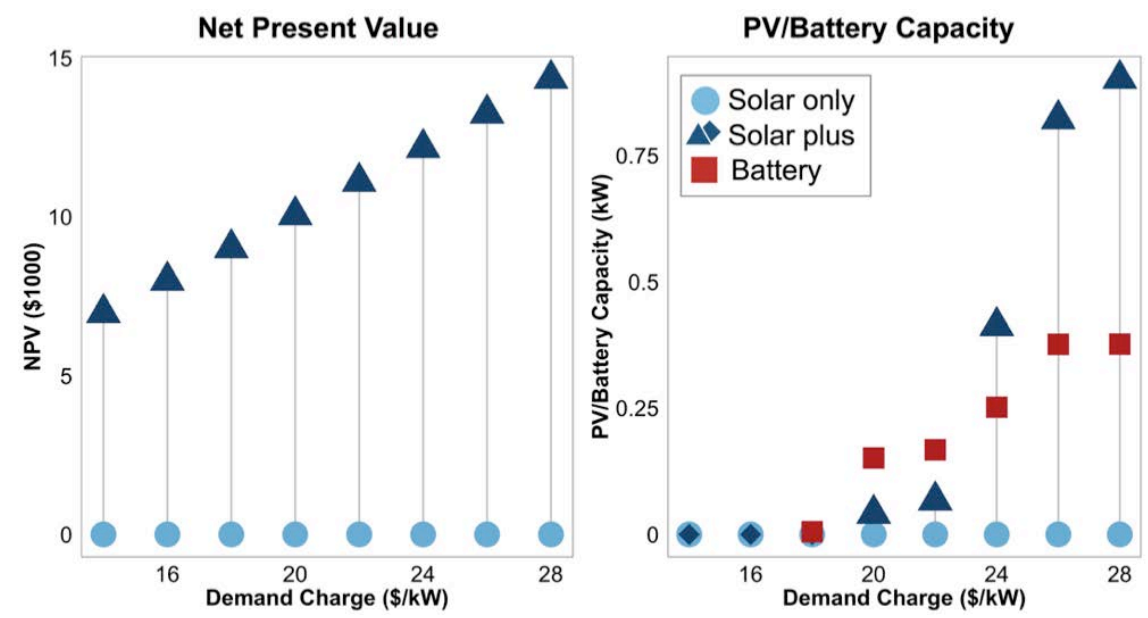

Figure 13. Solar plus economics under different demand charges (\$/kW)

Figure assumptions: flat volumetric rate is $\$ 0.06 / \mathrm{kWh}$, net metering rate is $\$ 0.03 / \mathrm{kWh}$ 


\subsection{Summary: Effects of Rate Structure and Net Metering Rates on Solar Plus Economics}

Table 3 summarizes the impacts of rate structure and net metering parameters on PV system values and incremental solar plus system value. The REopt analyses show that solar plus system values are always higher than standalone solar system values. The incremental value of solar plus relative to standalone solar is higher for customers with high flat retail rates, high peak TOU rates, low coincidence between TOU peak period and PV output, low net metering rates, and high demand charges. The results show that some rate reforms, such as lower net metering rates and TOU rate structures with non-coincident peak periods, negatively affect the economics of PV even with a solar plus approach. However, the solar plus approach can mitigate some of the negative impacts of evolving rate designs by providing extra incremental value to PV customers with low net metering rates and non-coincident TOU peak periods.

Table 3. Impacts of Rate Structure and Net Metering Parameters on PV System Values and Incremental Solar Plus System Value

\begin{tabular}{lccc}
\hline & $\begin{array}{c}\text { Impact on } \\
\text { Standalone Solar } \\
\text { System Value }\end{array}$ & $\begin{array}{c}\text { Impact on Solar Plus } \\
\text { System Value }\end{array}$ & $\begin{array}{c}\text { Impact on Incremental } \\
\text { Solar Plus System Value } \\
\text { Relative to Standalone } \\
\text { Solar System Value }\end{array}$ \\
\hline Flat retail rate & $\uparrow$ & $\uparrow$ & $\uparrow$ \\
\hline TOU peak rate & $\uparrow$ & $\uparrow$ & $\uparrow$ \\
\hline $\begin{array}{l}\text { Coincidence between } \\
\text { peak rate period and PV } \\
\text { output }\end{array}$ & $\uparrow$ & $\uparrow$ & $\downarrow$ \\
\hline Net metering (flat rate) & $\uparrow$ & $\uparrow$ & $\downarrow$ \\
\hline Net metering (TOU rate) & $\uparrow$ & $\uparrow$ & $\uparrow$ \\
\hline Demand charge & $*$ & $\uparrow$ & $\downarrow$ \\
\hline & $\uparrow:$ system value positively correlated with rate parameter \\
& $\downarrow:$ system value negatively correlated with rate parameter \\
\hline * Standalone system values are zero under all demand charges considered in our analysis.
\end{tabular}

* Standalone system values are zero under all demand charges considered in our analysis. 


\section{Case Studies}

We present the results of five case studies to explore the effects of rate structure and net metering rates on optimal solar plus systems based on actual utility rate designs. The case studies provide a variety of net metering rates, volumetric rates, TOU rate structures, and demand charges.

Consistent with Section 3, results are presented for a standalone solar scenario (REopt limited to deploying only PV) and a solar plus scenario.

The results of each case study are presented with the types and sizes of candidate technologies deployed and four metrics:

- PV generation (kWh/year): Annual generation of the PV system

- Electricity costs (\$/year): Customer's annual electricity payments

- System cost (\$): Total cost of PV array and solar plus technologies, including the NPV of future and ongoing costs (where applicable)

- NPV of investment (\$): NPV of the customer's standalone solar or solar plus investment, relative to the customer remaining at the same utility rate structure without these technologies ${ }^{10}$

Each case study includes a standard figure comparing customer load profiles and PV generation (in $\mathrm{kW}$ on the $\mathrm{y}$-axis) in the standalone solar and solar plus approaches for a sample summer week (Monday-Friday). Table 4 provides a guide to the terms in those figures.

Table 4. Case Study Load Profiles Figure Guide

\begin{tabular}{ll}
\hline Legend Description & Definition \\
\hline PV Generation & PV output \\
AC & Air-conditioning load \\
DHW & Domestic hot water load \\
Misc & Miscellaneous customer load (other than AC and DHW) \\
BESS & Battery energy storage load (system charging) \\
Net load & $\begin{array}{l}\text { Grid net load: total customer load at the utility meter; negative grid load reflects } \\
\text { excess PV output exported to the grid }\end{array}$ \\
\hline
\end{tabular}

Sections 4.1-4.5 present separate results and analysis for each case study. Section 5 provides a comparative analysis of the results from all five case studies.

\footnotetext{
${ }^{10}$ A discount rate of $6.2 \%$ is assumed (Feldman and Lowder 2014). National Institute of Standards and Technology annual energy cost escalation rates are assumed, with a period of analysis of 25 years.
} 


\subsection{Case Study 1: Hawaii Self-Supply Rate}

In late 2015, the Hawaiian Public Utilities Commission effectively ended net metering in Hawaii with the approval of a "self-supply" rate. ${ }^{11}$ Under the self-supply rate, PV customers may opt to pay TOU rates (Table 5) and are not compensated for excess output. Solar plus products are already on offer in Hawaii, thus the Hawaii case study serves partly to verify the empirical validity of REopt. The case study is based on a home in Honolulu.

Table 5. Hawaii Residential TOU Rate Structure

\begin{tabular}{lccc}
\hline & $\begin{array}{c}\text { Peak } \\
\text { (5 p.m.-10 }\end{array}$ & $\begin{array}{c}\text { Off-Peak.) } \\
\text { (10 } \text { p.m.-9 a.m.) }\end{array}$ & $\begin{array}{c}\text { Midday } \\
\text { (9 a.m.-5 } \text { p.m.) }\end{array}$ \\
\hline Rate $(\$ / \mathrm{kWh})$ & $\$ 0.35$ & $\$ 0.22$ & $\$ 0.13$ \\
\hline
\end{tabular}

\subsubsection{Results}

REopt deploys a 4.6-kW PV array for standalone solar and an 8-kW PV array coupled with a 7.8-kWh battery, smart AC unit, and smart domestic water heater for solar plus (Table 6). Solar plus results in a larger optimal PV system size compared with standalone solar, and it increases system NPV by about a factor of three.
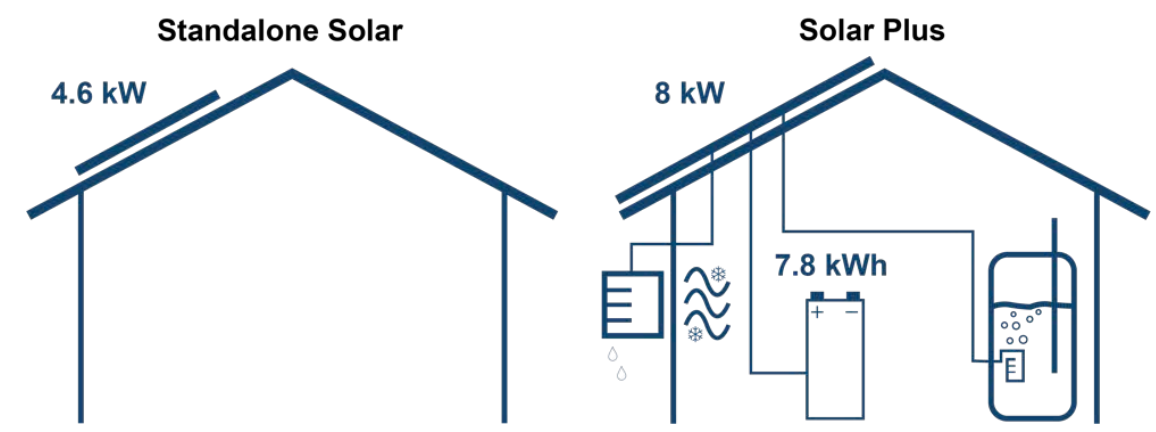

Table 6. REopt Results: Hawaii Self-Supply Rate

\begin{tabular}{lcc}
\hline & Standalone Solar & Solar Plus \\
\hline PV system size $(\mathrm{kW})$ & 4.6 & 8.0 \\
Battery size $(\mathrm{kWh} / \mathrm{kW})$ & - & $7.8 / 1.3$ \\
Smart water heater & - & Deployed \\
Smart AC & - & Deployed \\
\hline PV generation $(\mathrm{kWh} / \mathrm{yr})$. & 6,247 & 11,663 \\
Electricity savings $(\$ / \mathrm{yr})$. & $\$ 957$ & $\$ 2,690$ \\
System cost $(\$)$ & $\$ 5,933$ & $\$ 16,598$ \\
\hline NPV & $\$ 5,684$ & $\$ 16,851$ \\
\hline
\end{tabular}

${ }^{11}$ The reform included a second grid-supply tariff, but applications for this tariff have been exhausted. 


\subsubsection{Analysis}

Among the five case studies, REopt deploys the largest PV array $(8 \mathrm{~kW})$ and battery $(7.8 \mathrm{kWh})$ in the Hawaii case study. Further, the solar plus approach has the largest impact on system value in the Hawaii case study. The positive economics of solar plus in Hawaii are largely due to the TOU rate structure and lack of net metering.

The top pane of Figure 14 illustrates customer load profiles, grid net load, and PV output in the standalone solar approach. Home cooling loads increase simultaneously with increasing PV output in the morning into the midday. Peak PV output in the midday completely offsets coincident grid electricity use, driving grid net load to zero. PV output is curtailed under the terms of the self-supply rate; hence grid net load remains non-negative in the top pane of Figure 14 , even though the system could theoretically export excess output to the grid. Home cooling loads and miscellaneous loads increase in the late afternoon as PV output subsides. Grid net load and customer grid electricity use increase through the late afternoon and early evening during peak TOU rate hours (5-10 p.m.).

The bottom pane of Figure 14 illustrates customer load profiles, grid net load, and PV output in the solar plus approach. The smart AC unit and smart domestic water heater precool the home and preheat water with PV output each day, depicted in Figure 14 as increased cooling and water heating loads under the PV generation curve each day. The system delivers any excess output remaining after precooling and water heating to a $7.8-\mathrm{kWh}$ battery. The drift period of the smart $\mathrm{AC}$ unit is depicted in Figure 14 as a valley between the midday precooling peak and the lateafternoon cooling peak. Likewise, the smart domestic water heater drift is illustrated by the total absence of hot water draws in between PV output periods. Battery dispatching is depicted in Figure 14 as a lag between grid net load and customer load in the late afternoon peak, where battery electricity, rather than grid electricity, meets cooling loads. Owing to these dynamics, the customer's late-afternoon loads are visibly lower in the bottom pane of Figure 14 than in the top pane.

Solar plus increases system value by a factor of about three relative to standalone solar in the Hawaii case study. Increased system value stems from both increased solar self-use and grid arbitrage. The value of solar self-use increases the optimal PV system size from a 4.6-kW standalone solar PV system to an 8-kW solar plus PV system, and it reduces grid electricity use by about $40 \%$. Further, solar plus reduces grid electricity use at peak TOU rate hours far more effectively than does standalone solar. Through air precooling, water preheating, and battery dispatching, PV output during the low-rate midday hours ( $\$ 0.13 / \mathrm{kWh}$ from 9 a.m. to 5 p.m.) reduces grid electricity use during high-rate peak hours $(\$ 0.35 / \mathrm{kWh}$ from 5 p.m. to $10 \mathrm{p} . \mathrm{m}$.). The temporal shift of customer loads from peak hours to midday hours equates to an arbitrage value of $\$ 0.22 / \mathrm{kWh}$. 
Hawaii Self-Supply Rate (based on week in August)

TOU peak periods depicted by shaded columns
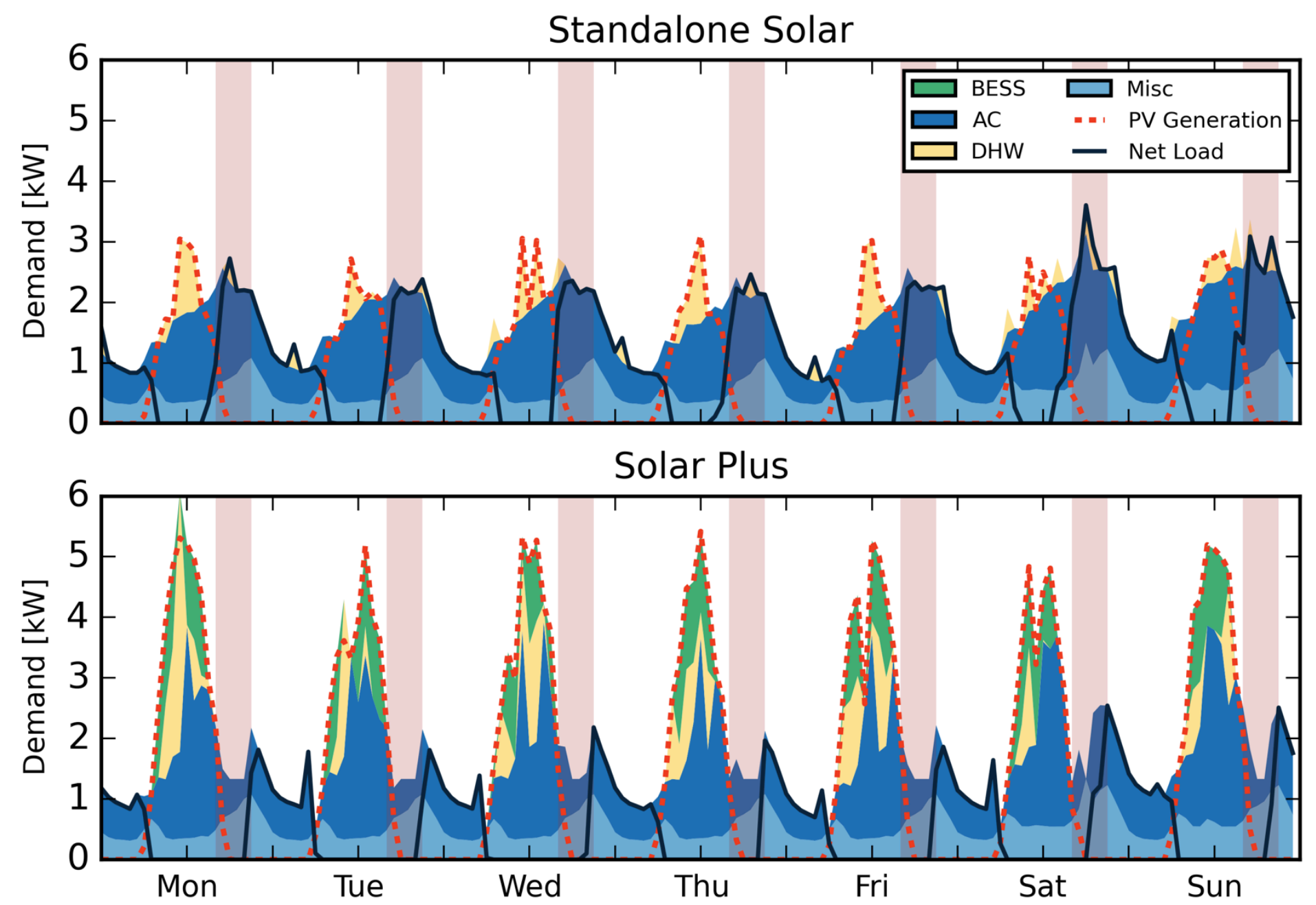

Figure 14. Hawaii case study PV and customer load profiles under standalone solar and solar plus scenarios 


\subsection{Case Study 2: Nevada Declining PV Export Rate}

In 2015 the Public Utilities Commission of Nevada approved a declining net metering rate schedule for PV customers. The ruling coupled declining net metering payments, from $\$ 0.092 / \mathrm{kWh}$ in 2016 to $\$ 0.026$ in 2028 , with falling volumetric rates $(\$ 0.111 / \mathrm{kWh}$ in 2016 to $\$ 0.102 / \mathrm{kWh}$ in 2028) and increasing basic service charges (\$17.90 in 2016 to $\$ 38.51$ in 2028). REopt optimizes a single decision at a given point in time based on assumed constant annual costs. We assume annualized volumetric charges of $\$ 0.106 / \mathrm{kWh}$, export credits of $\$ 0.055 / \mathrm{kWh}$, and service charges of $\$ 29.23$ month based on the Nevada declining net metering rate schedule. The case study is based on a home in Las Vegas.

\subsubsection{Results}

REopt deploys a 3.5-kW PV array for standalone solar and a 4.3-kW PV array coupled with a smart AC unit and a smart domestic water heater (but not a battery) for solar plus (Table 7). Solar plus increases system value by about $80 \%$.
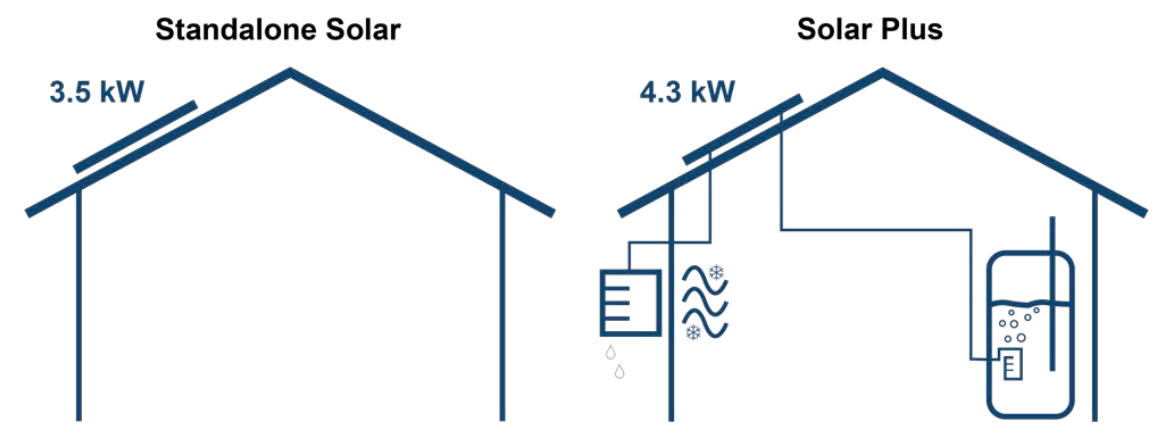

Table 7. REopt Results: Nevada Declining PV Export Rate

\begin{tabular}{lcc}
\hline & Standalone Solar & Solar Plus \\
\hline PV system size $(\mathrm{kW})$ & 3.5 & 4.3 \\
Battery size $(\mathrm{kWh} / \mathrm{kW})$ & - & - \\
Smart water heater & - & Deployed \\
Smart AC unit & - & Deployed \\
\hline PV generation $(\mathrm{kWh} / \mathrm{yr})$ & 5,868 & 7,323 \\
Electricity savings $(\$ / \mathrm{yr})$ & $\$ 404$ & $\$ 629$ \\
System cost $(\$)$ & $\$ 4,500$ & $\$ 5,615$ \\
\hline NPV & $\$ 1,117$ & $\$ 1,984$ \\
\hline
\end{tabular}




\subsubsection{Analysis}

In annualized terms, Nevada PV customers earn $\$ 0.055 / \mathrm{kWh}$ for excess PV output exported to the grid while paying $\$ 0.106 / \mathrm{kWh}$ for grid electricity. The value of solar self-use is thus about $\$ 0.051 / \mathrm{kWh}$ higher than the value of grid export. Solar plus improves system economics by increasing solar self-use.

The top pane of Figure 15 illustrates customer load profiles, grid net load, and PV output in the standalone solar approach. Home cooling loads increase concurrently with PV output in the morning to midday hours. PV output meets home cooling loads and drives grid net load to near or below zero throughout the midday (negative grid net load reflects grid exports for net metering). Home cooling loads increase significantly in the late afternoon as PV output subsides, causing grid net load to climb to compensate for falling PV output.

The bottom pane of Figure 15 illustrates customer load profiles, grid net load, and PV output in the solar plus approach. Home cooling and water heating loads are shifted under the PV output curve through the precooling and water preheating mechanisms. The smart AC unit drift period is depicted as a sharp valley in the home cooling load between the PV output curve and peak afternoon cooling load. The smart domestic water heater preheating mechanism reduces grid electricity use for hot water draws occurring outside of the PV output curve.

Unlike in the Hawaii case study, REopt does not deploy a battery in the Nevada case study despite a below-retail net metering rate of $\$ 0.055 / \mathrm{kWh}$. The economics, based only on customer bill savings from solar self-use, are insufficient to justify the relatively higher investment in an electrical battery. However, the same returns are sufficient to justify relatively minor investments in the smart domestic water heater and smart AC unit.

Solar plus increases system value by about $80 \%$ relative to standalone solar in the Nevada case study. Increased system value derives solely from increased solar self-use; grid arbitrage is unavailable owing to the case study's flat volumetric rate. The top pane of Figure 15 shows how the standalone solar PV array exports excess output to the grid for low-value net metering during most days of the week. In contrast, the bottom pane of Figure 15 shows that the solar plus PV array increases solar self-use. Hence, the solar plus system replaces low-value net metering (negative grid net load) with higher-value displaced grid electricity use through the air precooling/water preheating mechanisms. The higher value of PV output incentivizes a larger solar plus PV array. 


\section{Nevada Declining PV Export Rate (based on week in July)}
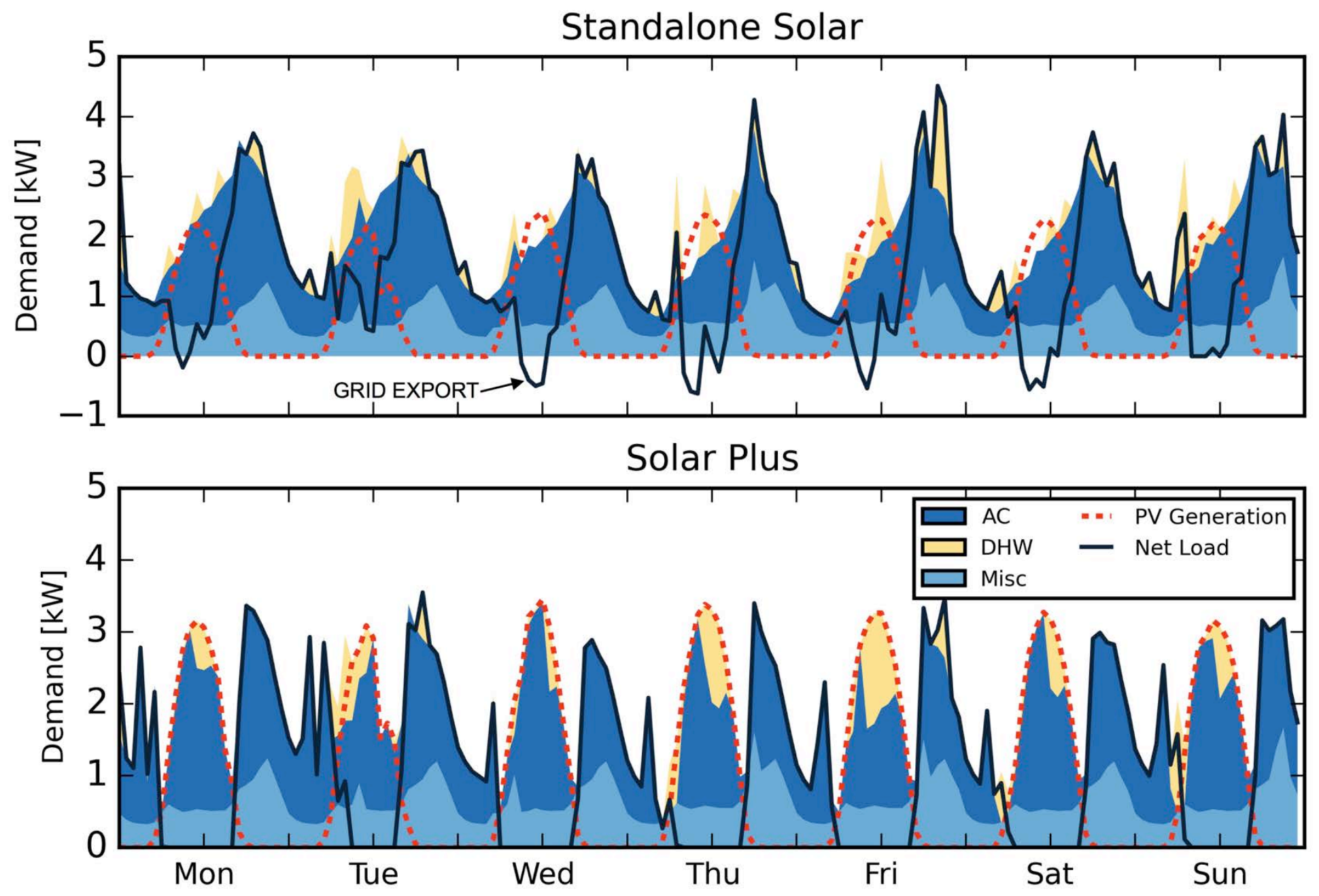

Figure 15. Nevada case study PV and customer load profiles under standalone solar and solar plus scenarios 


\subsection{Case Study 3: California PV Export with TOU Rates}

In 2016, California amended its net metering rules to require all PV customers to participate in TOU rates. Table 8 displays the assumptions for the TOU scenario based on a hypothetical customer in San Francisco. Customers are compensated for PV exports at the same TOU rates (generally off-peak, given that most PV exports occur outside of peak hours). ${ }^{12}$

Table 8. California Residential TOU Rate Assumptions

\begin{tabular}{lcc}
\hline Season & Off-Peak & Peak (4 p.m.-9 p.m.) \\
\hline Summer (June-September) & $\$ 0.26$ & $\$ 0.36$ \\
\hline Winter (October-May) & $\$ 0.20$ & $\$ 0.22$ \\
\hline
\end{tabular}

\subsubsection{Results}

REopt deploys a 6.5-kW PV array under both approaches, coupled with a smart domestic water heater under solar plus (Table 9). The battery and smart AC unit are not deployed.
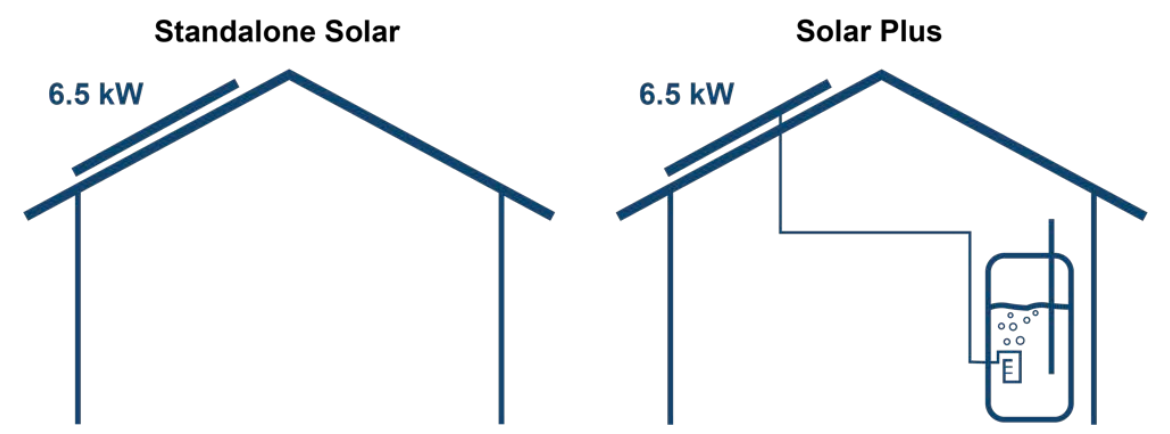

Table 9. REopt Results: California PV Export with TOU Rates

\begin{tabular}{lcc}
\hline & Standalone Solar & Solar Plus \\
\hline PV system size $(\mathrm{kW})$ & 6.5 & 6.5 \\
Battery size $(\mathrm{kWh} / \mathrm{kW})$ & - & - \\
Smart water heater & - & Deployed \\
Smart AC unit & - & - \\
\hline PV generation $(\mathrm{kWh} / \mathrm{yr})$ & 9,626 & 9,626 \\
Electricity savings $(\$ / \mathrm{yr})$ & $\$ 560$ & $\$ 943$ \\
System cost & $\$ 8,398$ & $\$ 8,648$ \\
\hline NPV & $\$ 19,386$ & $\$ 20,637$ \\
\hline
\end{tabular}

\footnotetext{
${ }^{12}$ For the sake of simplicity, we assume PV customers do not pay fixed charges.
} 


\subsubsection{Analysis}

Relative to other case studies, solar plus has little impact on system configuration and customer economics in the California case study. Solar plus does not affect the optimal PV system size and only marginally affects system value. The California case study is the only case in which the smart AC unit is not deployed, owing to the mild climate in San Francisco. Importantly, California is the only case study with full retail rate net metering. The relatively modest impact of solar plus is due to full retail rate net metering and the TOU rate structure.

The top pane of Figure 16 illustrates customer load profiles, grid net load, and PV output in the standalone solar approach. Unlike in other case studies, home cooling loads are insignificant owing to the temperate San Francisco climate. Customer load consists primarily of miscellaneous base load and hot water draws. 13 Full retail rate net metering results in an oversized 6.5-kW PV system with daily excess output generated for grid export, depicted in Figure 16 as negative grid net loads every day of the week.

The bottom pane of Figure 16 illustrates customer load profiles, grid net load, and PV output in the solar plus approach. Solar plus has only the marginal effect of shifting some hot water load under the PV output curve.

The absence of the AC unit illustrates the role of climate in the analysis. In a typical TOU structure, customers could accrue savings by using the smart AC unit to perform grid arbitrage. In San Francisco, AC loads are insignificant and generally occur simultaneously with PV production, if at all. Under TOU net metering, the modeled San Francisco home has no savings opportunity if no significant cooling requirements exist during peak rate hours. As a result, the customer has no incentive to invest in the smart AC unit. However, REopt may have deployed the smart $\mathrm{AC}$ unit for other California customers in warmer climates with more significant cooling requirements.

Solar plus marginally increases system value relative to standalone solar, primarily owing to grid arbitrage. The solar plus system uses the preheating mechanism in the smart domestic water heater to perform this arbitrage between peak hours (4-9 p.m.) and off-peak hours under the PV output curve.

\footnotetext{
${ }^{13}$ Although most homes in California use gas-fired domestic water heaters, we assume every home in all five case studies has an electric water heater.
} 
California PV Export with TOU Rates (based on week in July-August)

TOU peak periods depicted by shaded columns
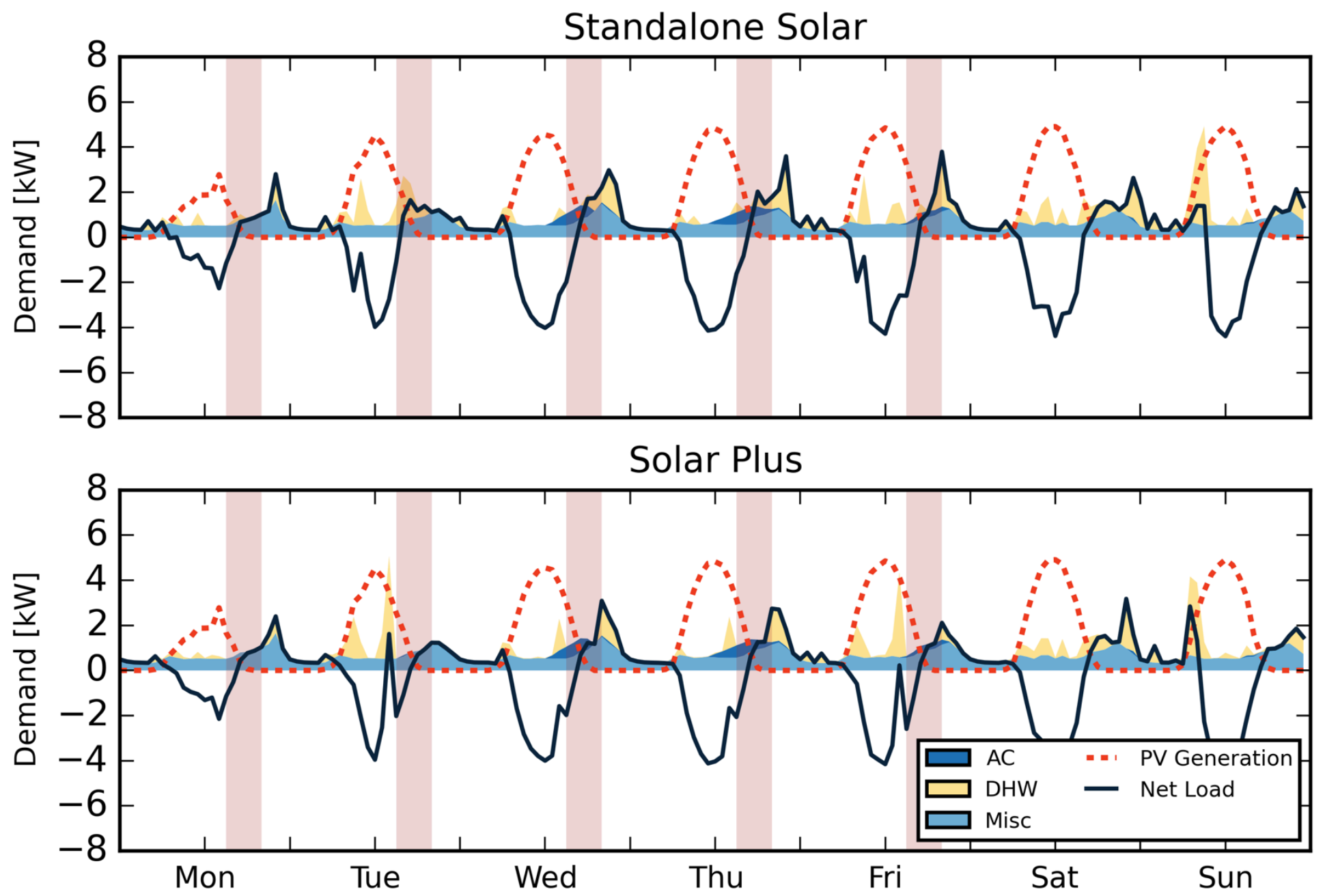

Figure 16. California case study PV and customer load profiles under standalone solar and solar plus scenarios 


\subsection{Case Study 4: Arizona Super Peak Tariff}

The Arizona "super peak" tariff is designed to incentivize customers to reduce electricity use during peak hours of the summer months. Customers pay different peak and off-peak rates depending on the time of year, and they pay a "super peak" rate in June through August (Table 10). Customers are compensated for excess PV output at about $\$ 0.03 / \mathrm{kWh}$. ${ }^{14}$ The case study is based on a home in Phoenix.

Table 10. Arizona Residential Super Peak Tariff Rate Structure

\begin{tabular}{lccc}
\hline Season & $\begin{array}{c}\text { Peak* (12 p.m.-7 } \\
\text { p.m.) }\end{array}$ & $\begin{array}{c}\text { Off-peak (7 p.m.-12 } \\
\text { p.m.) }\end{array}$ & $\begin{array}{c}\text { Super Peak (3 p.m.-6 } \\
\text { p.m.) }\end{array}$ \\
\hline November-April & $\$ 0.20$ & $\$ 0.06$ & - \\
May-October & $\$ 0.24$ & $\$ 0.06$ & $\$ 0.47^{\star *}$ \\
\hline
\end{tabular}

*Weekdays only, ** June-August

\subsubsection{Results}

REopt deploys a 4.9-kW PV array for standalone solar and a 4.2-kW PV array with a smart AC unit and smart domestic water heater for solar plus, but it does not deploy a battery (Table 11).

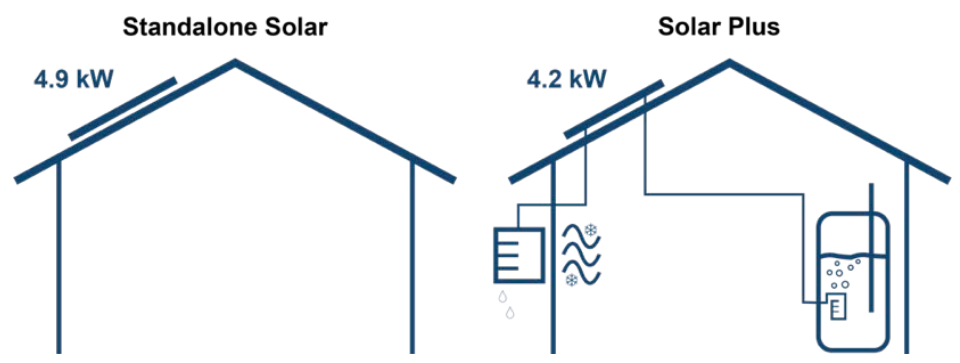

Table 11. REopt Results: Arizona Super Peak Tariff

\begin{tabular}{lcc}
\hline & Standalone Solar & Solar Plus \\
\hline PV system size $(\mathrm{kW})$ & 4.9 & 4.2 \\
Battery size $(\mathrm{kWh} / \mathrm{kW})$ & - & - \\
Smart water heater & - & Deployed \\
Smart AC unit & - & Deployed \\
PV generation $(\mathrm{kWh} / \mathrm{yr})$ & 8,062 & 6,930 \\
Electricity savings $(\$ / \mathrm{yr})$ & $\$ 940$ & $\$ 1,229$ \\
System cost & $\$ 6,367$ & $\$ 5,474$ \\
\hline NPV & $\$ 5,968$ & $\$ 9,565$ \\
\hline
\end{tabular}

${ }^{14}$ Based on EPR-2 rate. May-October: on-peak $=\$ 0.02989 / \mathrm{kWh}$, off-peak $=\$ 0.0289 / \mathrm{kWh}$. November-April: onpeak $=\$ 0.0304 / \mathrm{kWh}$, off-peak $=\$ 0.02831 / \mathrm{kWh}$. 


\subsubsection{Analysis}

Solar plus increases system value by about $60 \%$ relative to standalone solar, despite resulting in a smaller optimal PV system size. This result is driven by the importance of grid arbitrage relative to solar self-use in this scenario. The value of increased solar self-use is relatively small, given that the peak period (12-7 p.m.) largely coincides with PV generation. However, the grid arbitrage opportunity is relatively large, especially for reducing grid electricity use during the super peak (3-6 p.m., June-August).

The top pane of Figure 17 illustrates customer load profiles, grid net load, and PV output in the standalone solar approach. The warm Arizona climate results in significant cooling loads with late-afternoon peaks each day. REopt deploys a slightly oversized 4.9-kW PV array to reduce customer load during the peak period and particularly during the super peak. The oversized system generates excess output that is exported to the grid (depicted as negative grid net load in the top pane of Figure 17). However, PV output subsides and grid net load increases at the tail end of the peak rate period. The customer peak load occurs almost entirely after PV output has ceased, owing to late-afternoon home-cooling needs.

The bottom pane of Figure 17 illustrates customer load profiles, grid net load, and PV output in the solar plus approach. Solar plus reshapes customer load profiles in two ways. First, the system shifts cooling loads and, to a lesser extent, water heating under the PV production curve. These shifts reduce customer grid electricity use during peak rate hours in the late afternoon. Second, the smart AC unit precools the home during off-peak hours (7 p.m.-12 p.m.), depicted in Figure 17 as spikes in cooling load preceding PV output on most days.

Solar plus increases system value in the Arizona super peak case study through a more costeffective, smaller solar plus PV array (see also Section 4.5). This occurs because of the customer load profiles, the low value of net-metered excess PV output, and the TOU rate structure in the case study. The oversized 4.9-kW PV array is an inefficient solution to the economic optimization problem, given that the oversized system generates low-value excess output $(\sim \$ 0.03 / \mathrm{kWh})$. Conceptually, REopt seeks to simultaneously reduce the customer's peak load and minimize low-value grid exports. Solar plus offers a more elegant solution to the optimization problem. Through load shifting, solar plus reduces the customer's peak load so effectively that less PV capacity is required to reduce customer load in the afternoon tail of PV output. REopt is therefore able to deploy a smaller, more cost-effective PV array that nearly eliminates grid exports while also reducing customer peak load. 
Arizona Super Peak Tariff (based on week in July)

TOU peak periods depicted by light shaded columns, super peaks depicted by dark shaded columns
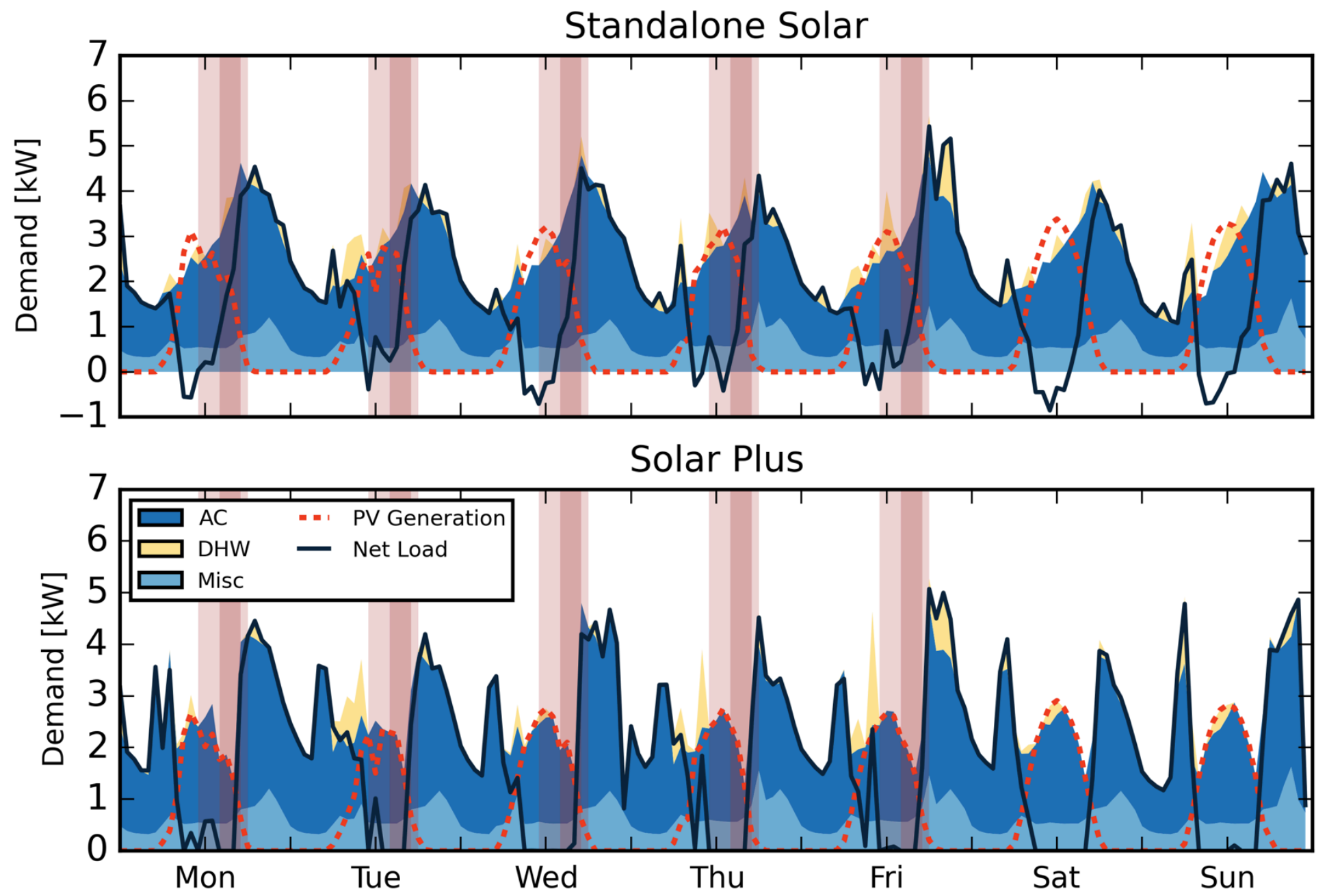

Figure 17. Arizona super peak case study PV and customer load profiles under standalone solar and solar plus scenarios 


\subsection{Case Study 5: Arizona Demand Tariff}

The Arizona demand tariff includes a monthly demand charge based on the customer's maximum demand during peak hours (weekdays $12-7$ p.m.). The customer's peak demand is based on average demand in the hour in which their maximum demand in a given billing period occurs. The tariff structure includes TOU rates (Table 12). Customers are compensated for excess PV output at about $\$ 0.03 / \mathrm{kWh} .{ }^{15}$ Case study is based on a home in Phoenix.

Table 12. Arizona Residential Demand Tariff Rate Structure

\begin{tabular}{lccc}
\hline Season & On-peak* $^{*}$ (12-7 p.m.) & Off-peak (7-12 p.m.) & Demand Charge (\$/kW) \\
\hline November-April & $\$ 0.06$ & $\$ 0.04$ & $\$ 9.30$ \\
May-October & $\$ 0.09$ & $\$ 0.04$ & $\$ 13.50$ \\
\hline
\end{tabular}

*Weekdays only

\subsubsection{Results}

REopt deploys a 2.7-kW PV array for standalone solar and a 2.6-kW PV array coupled with a smart AC unit, 0.3-kWh battery, and smart domestic water heater for the solar plus approach (Table 13).

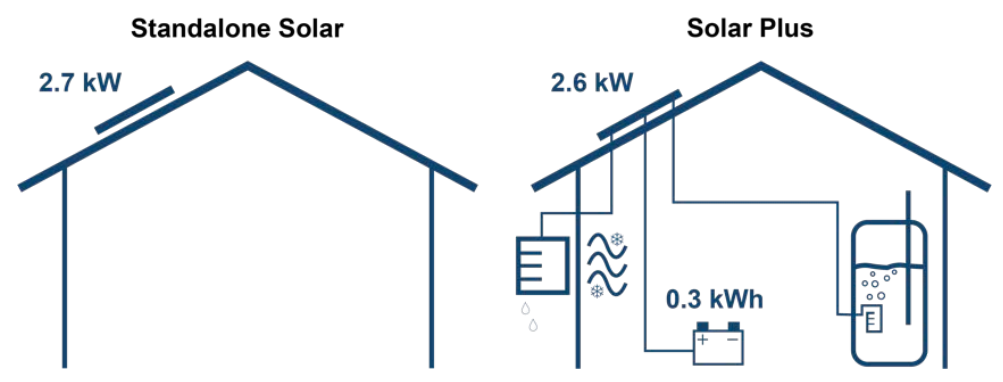

Table 13. REopt Results: Arizona Demand Tariff

\begin{tabular}{lcc}
\hline & Standalone Solar & Solar Plus \\
\hline PV system size $(\mathrm{kW})$ & 2.7 & 2.6 \\
Battery size $(\mathrm{kWh} / \mathrm{kW})$ & - & $0.3 / 0.2$ \\
Smart water heater & - & Deployed \\
Smart AC unit & - & Deployed \\
\hline PV generation $(\mathrm{kWh} / \mathrm{yr})$ & 4,482 & 4,182 \\
Electricity savings $(\$ / \mathrm{yr})$ & $\$ 357$ & $\$ 848$ \\
System cost & $\$ 3,540$ & $\$ 4,039$ \\
\hline NPV & $\$ 750$ & $\$ 6,651$ \\
\hline
\end{tabular}

${ }^{15}$ Based on EPR-2 rate. May-October: on-peak $=\$ 0.02989 / \mathrm{kWh}$, off-peak $=\$ 0.0289 / \mathrm{kWh}$. November-April: onpeak $=\$ 0.0304 / \mathrm{kWh}$, off-peak $=\$ 0.02831 / \mathrm{kWh}$. 


\subsubsection{Analysis}

The top pane of Figure 18 illustrates customer load profiles, grid net load, and PV output in the standalone solar approach. The warm climate results in significant cooling loads, with lateafternoon peaks occurring after PV output. The relatively small $2.7-\mathrm{kW}$ PV array always generates less than coincident load, and grid net load remains positive throughout the day. The small system size is due to the low net metering rate, and it may be further driven by the demand charge tariff structure (Darghouth et al. 2017).

Solar plus increases system value primarily through grid arbitrage. The bottom pane of Figure 18 illustrates customer load profiles, grid net load, and PV output in the solar plus approach. The optimal PV system size decreases slightly in the solar plus approach, to $2.6 \mathrm{~kW}$. Customer load profiles under the PV output curve are largely unchanged between the two scenarios, with no evidence of air precooling and water preheating and only trivial levels of excess output delivered to the battery. Nonetheless, solar plus visibly reshapes customer load profiles owing to grid arbitrage opportunities. The system uses the smart AC unit and the smart domestic water heater to precool the home and preheat water with grid electricity most mornings during off-peak hours. In other words, solar plus has relatively little effect on the amount of grid electricity use but rather provides value by temporally shifting grid electricity use. Solar plus increases system value by almost a factor of nine while only reducing grid electricity use by about $6 \%$. 
Arizona Demand Tariff (based on week in July)

TOU peak periods depicted by shaded columns
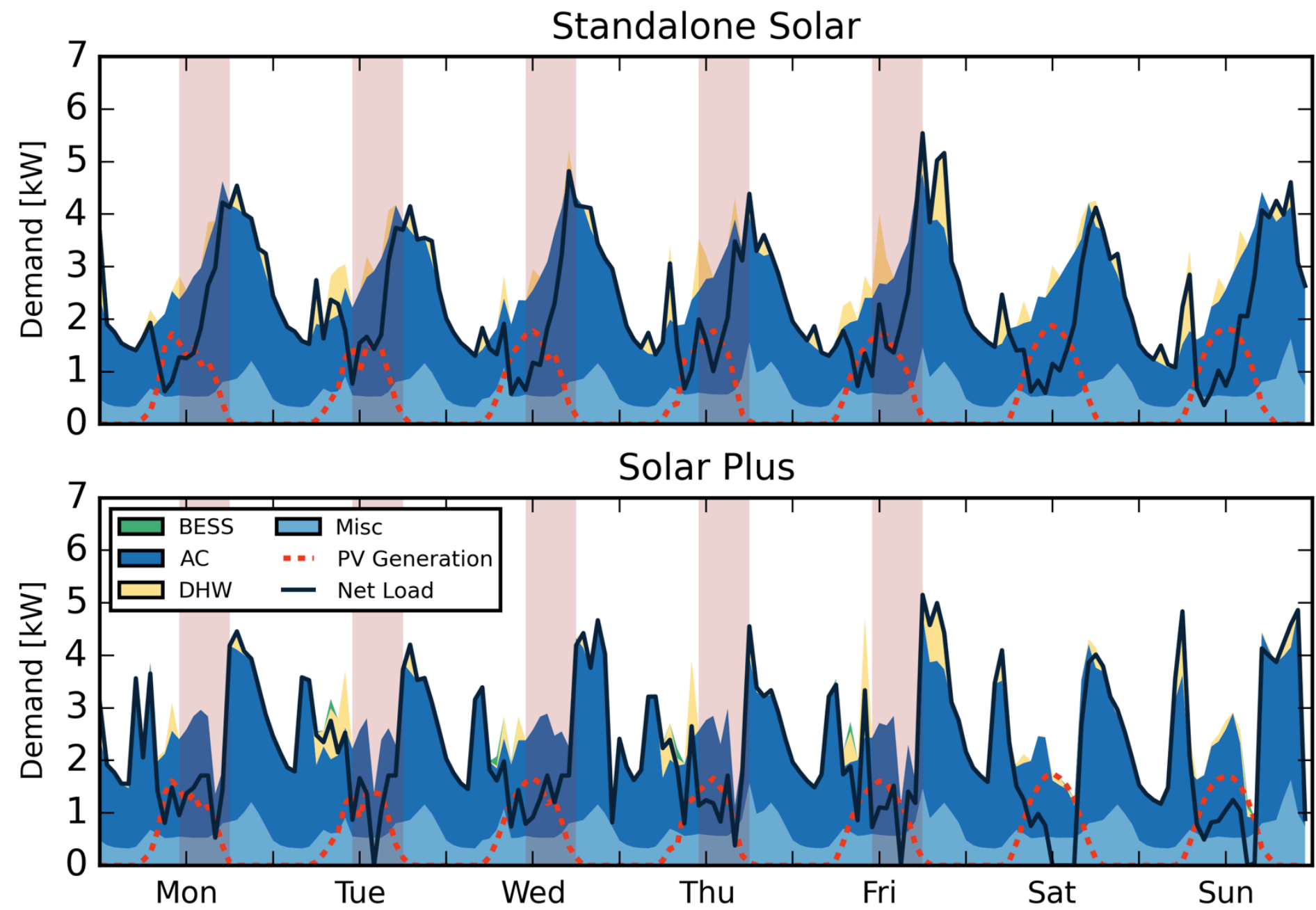

Figure 18. Arizona demand tariff case study PV and customer load profiles under standalone solar and solar plus scenarios 


\section{Case Study Discussion and Sensitivity Analyses}

REopt deploys at least one candidate technology in addition to PV in all five case studies (Figure 19). In this section, we discuss the factors that drive optimal solar plus systems and explain differences across the case studies.

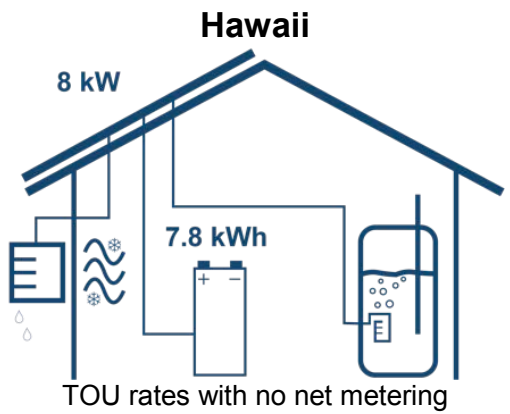

Arizona Super Peak

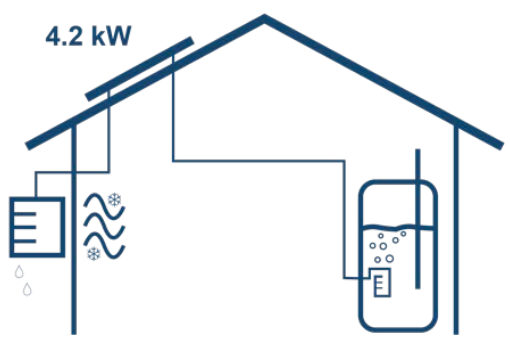

TOU rates including a high "super-peak" rate in the summer months, net metering $\sim \$ 0.03 / \mathrm{kWh}$.

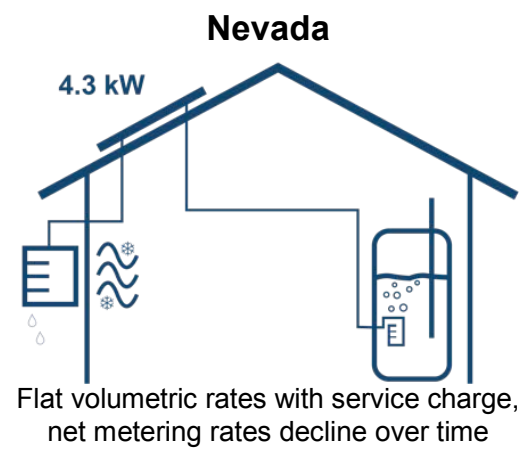

Arizona Demand Tariff

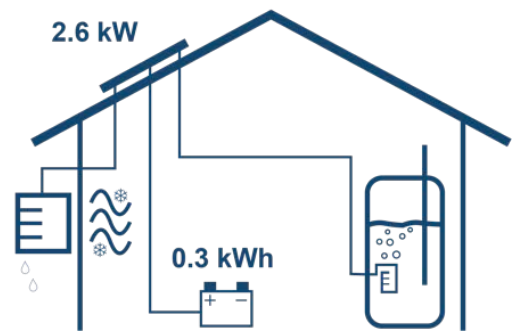

TOU rates and a demand charge based on maximum demand $(\mathrm{kW})$, net metering $\sim \$ 0.03 / \mathrm{kWh}$
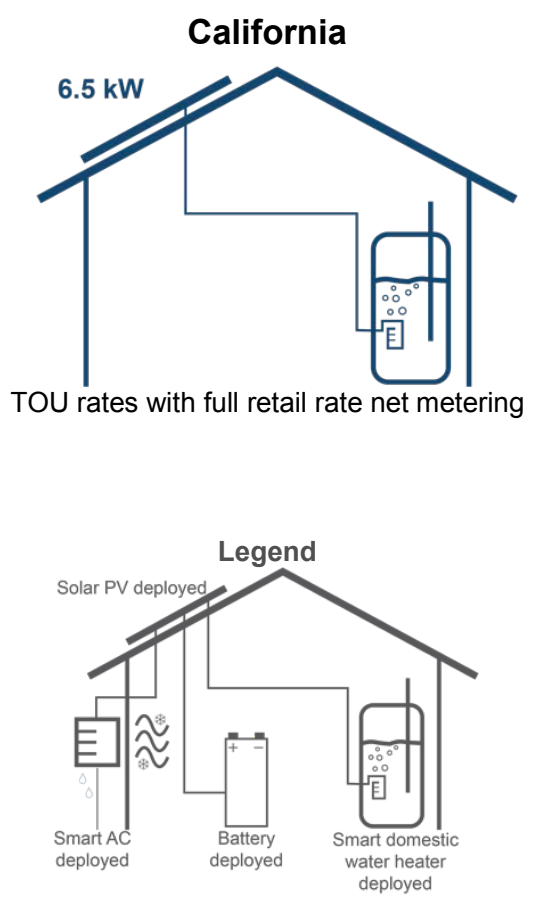

Figure 19. Optimal solar plus deployments across five case studies

Our analysis has two specific limitations. First, we only analyze values from customer bill savings. Other potential customer values such as resiliency during grid outages are excluded, as are societal and grid-level benefits. ${ }^{16}$ Hence the analysis likely undervalues energy storage devices capable of delivering additional services. Second, the REopt candidate technologies are modeled representations of actual market products. It is unlikely that off-the-shelf smart home devices could perform as efficiently in reality as the devices perform within the REopt optimization model. The presented operation of the technologies should be viewed as maximum technical potential for the specific technologies modeled.

\subsection{Effects of Solar Plus on PV Deployment}

Solar plus affects the optimal PV system size in every case study with below-retail rate net metering (Figure 20). The results suggest that rate structures and net metering determine optimal solar plus PV system size.

\footnotetext{
${ }^{16}$ See Fitzgerald et al. (2015) for a survey of energy storage values.
} 


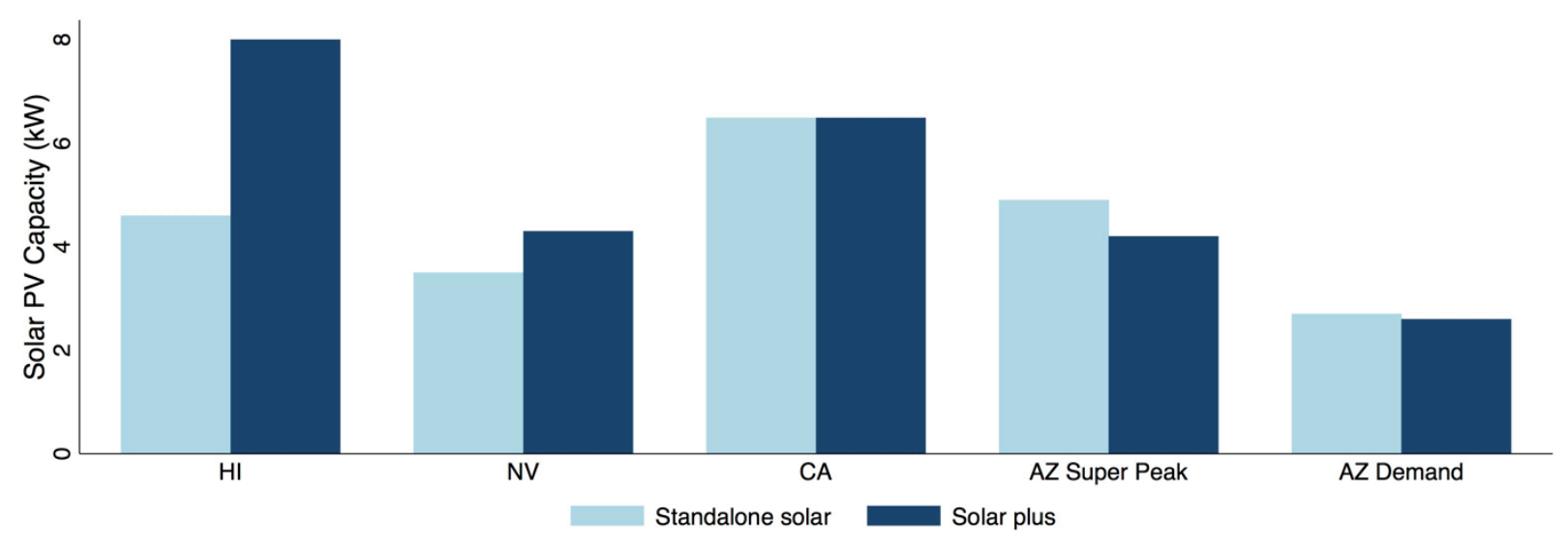

Figure 20. Optimal PV system sizes across case studies and approaches

In Nevada, the flat retail rate and below-retail rate net metering incentivize increased solar selfuse. Customers can use solar plus technologies to temporally shift customer loads under the PV production curve and displace low-value net metering with higher-value grid electricity savings. This solar self-use value results in a large solar plus PV system size relative to the standalone solar approach.

However, the effects of solar plus on PV system size are more nuanced with the TOU case studies. In Hawaii, PV output is mostly non-coincident with the peak rate period. As a result, customers have an incentive to generate and store excess PV output to reduce peak electricity use. This load shifting equates to a value of $\$ 0.35 / \mathrm{kWh}$ for increased solar self-use, and it results in a relatively large 8-kW PV system. In contrast, PV output in Arizona largely coincides with the peak rate period, and the value of increased self-use through customer load shifting is primarily determined by lower off-peak rates. Thus there is relatively little incentive to generate and store excess PV output to reduce off-peak grid electricity use.

Overall, the solar plus approach results in more cost-effective PV system sizes, which may be larger or smaller than standalone solar PV systems. For instance, the solar plus approach reduces optimal PV system size in the Arizona case studies. In the Arizona super peak case, REopt deploys a slightly oversized $4.9-\mathrm{kW}$ standalone PV system. The standalone PV system reduces the customer's grid electricity use during the peak and super peak periods, but it also generates low-value $(\$ 0.03 / \mathrm{kWh})$ excess output. Through the solar plus approach, home precooling and water preheating reduce customer load during the peak and super peak periods. REopt responds to the customer's lower peak/super peak load by deploying a smaller 4.2-kW PV system. The smaller system is more cost-effective, because it generates almost no low-value excess output.

\subsection{Deploying Low-Cost Modifications before High-Cost Batteries}

REopt deploys both the smart domestic water heater and the smart AC unit in four of the five case studies, and it deploys the smart water heater in all cases studies. In contrast, it deploys batteries in only two case studies with rate structures and low net metering rates that justify the larger investment. These results are consistent with previous studies (Castillo-Cagigal et al. 2011; Parra et al. 2016), in which lower-cost load-control devices are deployed first and more often than batteries. These results suggest that, if low-cost modifications to existing equipment (e.g., smart domestic water heaters, smart AC units) are available, they may generally be 
deployed more than batteries for solar plus systems, assuming current rate structures and battery costs.

However, battery costs have fallen over time, and the decline is projected to continue (Manghani 2014). We perform a sensitivity analysis to assess battery deployment under different battery cost assumptions. We allow battery costs to fall from $100 \%$ to $25 \%$ of their current costs ( $\$ 1,060 / \mathrm{kWh}, \$ 1,271 / \mathrm{kW}$-alternating current), and we use REopt to optimize deployed battery capacity along this range of costs. Figure 21 displays the results of the sensitivity analysis for the five case studies.

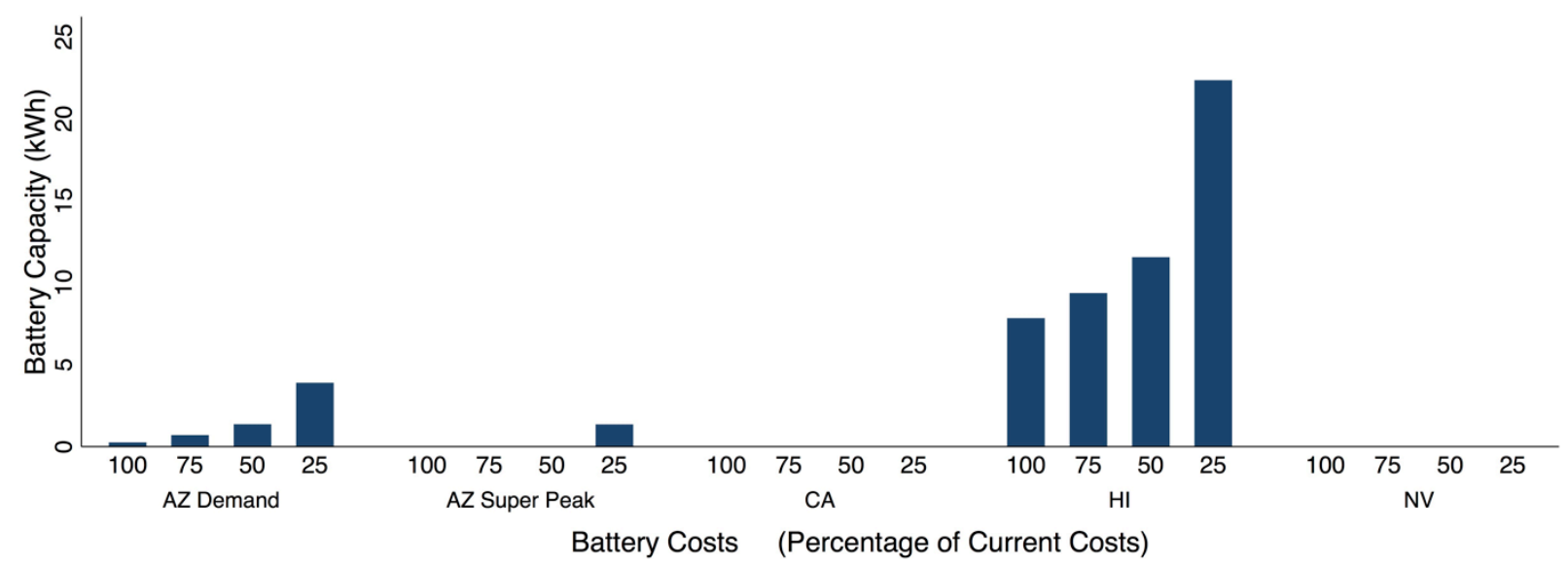

Figure 21. Sensitivity of battery deployment to battery costs in all case studies

A $50 \%$ reduction in battery costs increases optimal battery capacity (kWh) by $49 \%$ in Hawaii, and by more than a factor of four in the Arizona demand case study. REopt deploys a 1.3-kWh battery in the Arizona super peak study at $25 \%$ of battery costs assumed in this analysis. These results illustrate the sensitivity of optimal battery installed capacity to battery costs. Further, the results foretell an expanded role for batteries in solar plus systems as battery costs decline in some contexts. Nonetheless, REopt does not deploy batteries in the California and Nevada case studies, even after $75 \%$ cost reductions.

\subsection{Increasing System Value via Solar Plus}

The NPVs of the optimal solar plus systems span more than a factor of nine across the case studies, from $\$ 1,984$ to $\$ 20,637$ (Figure 22). Solar plus increases system NPV relative to standalone solar in all five case studies, by about a factor of three on average.

The effect of solar plus on NPV depends on net metering rates and rate structure. Solar plus has significant impacts on NPV in cases with low net metering rates (e.g., Hawaii, Arizona) but a relatively marginal impact in California, which has full retail rate net metering. With regard to rate structure, TOU rates and demand charges enable grid arbitrage and add value to load shifting. Under flat rates, grid electricity use and grid costs fall at the same rate. For example, solar plus results in a $24 \%$ reduction in both grid electricity use and grid electricity costs in the Nevada case study. In contrast, under Hawaii's TOU structure, solar plus reduces grid electricity use by $45 \%$ and reduces grid electricity costs by $56 \%$. More dramatically, solar plus reduces grid electricity use by only $6 \%$ in the Arizona demand tariff case study, but it reduces grid electricity 
costs by $38 \%$. Thus solar plus generally has a greater impact on system value under TOU and demand charge rate structures.

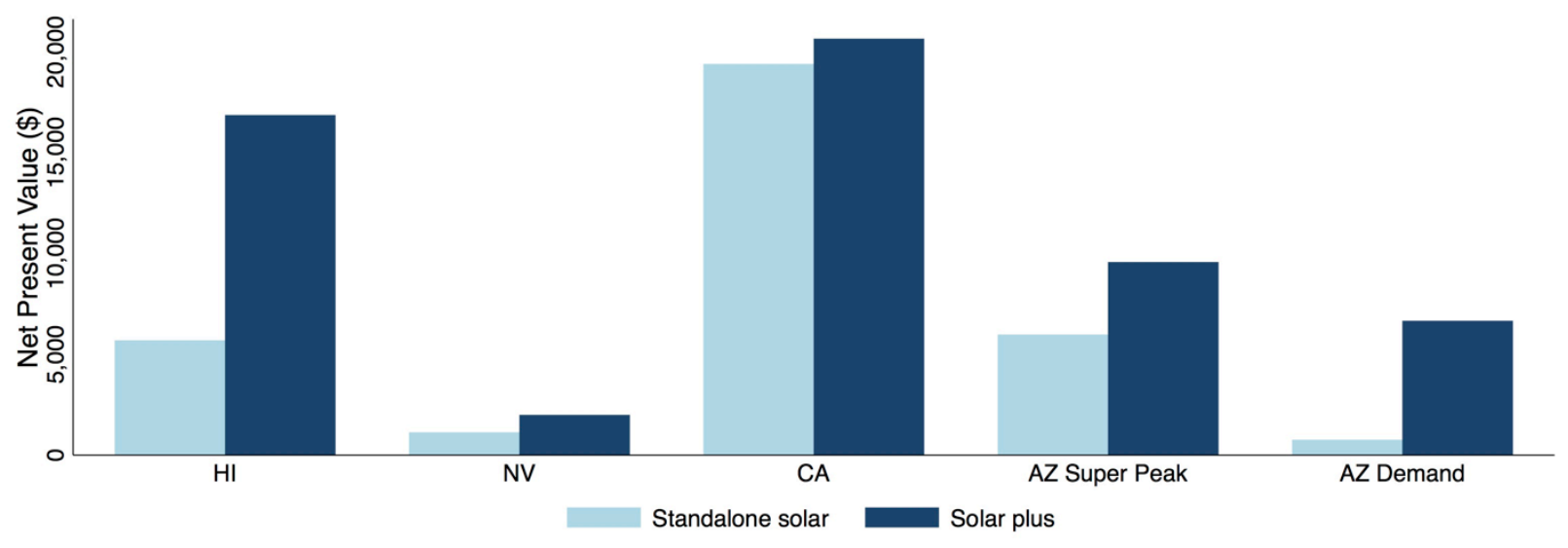

Figure 22. System NPV across case studies and approaches 


\section{Conclusion}

The intersection of distributed PV, energy storage, and customer load control gives rise to the "solar plus" approach. Solar plus allows customers to increase solar self-use and realize value from more PV generation by temporally shifting customer load under the PV production curve. We use NREL's REopt model to explore the economics of solar plus under various utility rate structures and net metering rates. In five case studies, we used the model to deploy different configurations of PV, electrical storage (battery), smart domestic water heaters, and smart AC units in response to different market environments. In general, our results indicate the solar plus approach improves the customer economics of PV. The results have four primary implications:

Solar plus increases PV system value. The solar plus approach increases the NPV of the customer's investment (relative to standalone solar) in all five case studies. Increased system values derive from a combination of increased solar self-use and energy arbitrage opportunities provided by certain rate structures.

Solar plus generally affects the optimal PV system size. Solar plus results in more costeffective PV system sizes. Depending on rate structures, solar plus PV systems may be larger or smaller than standalone solar PV systems.

The solar plus approach may mitigate some of the negative impacts of declining net metering rates and evolving rate structures on PV economics. The incremental value of solar plus, relative to standalone solar, is greatest for customers with low net metering rates as well as customers with TOU rates and a peak period that does not coincide with PV output.

Current utility rate structures and battery costs generally do not support battery deployment based on customer bill savings alone. In the near term, low-cost modifications to existing technologies such as smart domestic water heaters and smart AC units may take primacy over batteries in solar plus applications. Continued battery cost reductions suggest batteries may be increasingly economical in solar plus systems. Nevertheless, battery costs are less significant than rate structures in how they affect battery optimization.

These conclusions point to several potential pathways for future research. First, future studies could incorporate additional technologies such as electric vehicles, controllable refrigeration, other controllable appliances, and controllable home heating. Second, future research could explore solar plus under new rates and model how proposed rate reforms would affect the economics of solar plus. Finally, future work could incorporate into solar plus deployment models additional value streams such as grid-outage resiliency and ancillary services.

In conclusion, our analysis illustrates the customer-side economics that are driving emerging markets for solar plus technologies. Solar plus is becoming an increasingly viable model for optimizing PV customer economics in an evolving rate environment. 


\section{Glossary}

Coincident load

Deadband

Excess solar output

Grid arbitrage

Grid net load

Load control

Net metering

Standalone solar

Solar plus

Solar self-use
Solar customer electricity use that occurs simultaneously with PV production

Temperature range maintained by a temperature-control device

PV production $(\mathrm{kWh})$ that exceeds the customer's coincident load

Shifting electricity use from a high-cost period to a low-cost period

The residual of the customer's load $(\mathrm{kW})$ that remains after subtracting PV output: net load = customer load - PV output.

The ability to dictate when and how certain components of a customer's home draw solar-generated or grid electricity

A policy that requires utilities to compensate PV customers for excess output through utility bill credits

A PV system deployed without solar plus technologies

An approach to PV deployment that optimizes customer economics through the coupling of PV with energy-storage and load-control technologies

Onsite use of PV electricity (as opposed to exporting electricity to the grid) 


\section{References}

Ardani, K., E. O’Shaughnessy, R. Fu, C. McClurg, J. Huneycutt, and R. Margolis. 2017. Installed Costs and Deployment Barriers for Residential Solar Photovoltaics (PV) with Energy Storage. Golden, CO: National Renewable Energy Laboratory. NREL/TP-7A40-67474.

Braff, W., J. Mueller, and J. Trancik. 2016. "Value of Storage Technologies for Wind and Solar Energy." Nature Climate Change 6: 964-970.

Bronski, P., J. Creyts, L. Guccione, M. Madrazo, J. Mandel, B. Rader, D. Seif, P. Lilienthal, J. Glassmire, J. Abromowitz, M. Crowdis, J. Richardson, E. Schmitt, and H. Tocco. 2014. The Economics of Grid Defection. Boulder, CO: Rocky Mountain Institute.

Burch, J., and P. Erikson. 2004. Using Ratings Data to Derive Simulation-Model Inputs for Storage-Tank Water Heaters. Golden, CO: National Renewable Energy Laboratory. NREL/CP550-36035.

Cao, S., A. Hasan, and K. Sirén. 2013. "Analysis and Solution for Renewable Energy Load Matching for a Single-Family House." Energy and Buildings 65: 398-411.

Castillo-Cagigal, M., E. Caamaño-Martín, E. Matallanas, D. Masa-Bote, A. Gutiérrez, F. Montasterio-Huelin, and J. Jiménez-Leube. 2011. "PV Self-Consumption Optimization with Storage and Active DSM for the Residential Sector.” Solar Energy 85: 2338-2348.

Cutler, D., J. Winkler, N. Kruis, C. Christensen, and M. Brandemuehl. 2013. Improved Modeling of Residential Air Conditioners and Heat Pumps for Energy Calculations. Golden, CO: National Renewable Energy Laboratory. NREL/TP-5500-56354.

Darghouth, N., G. Barbose, A. Mills, R. Wiser, P. Gagnon, and L. Bird. 2017. Exploring Demand Charge Savings from Residential Solar. Berkeley, CA: Lawrence Berkeley National Laboratory.

DOE (U.S. Department of Energy). 2009. Water Heater Market Profile. Washington, DC: U.S. Department of Energy.

Dyson, M., J. Mandel, P. Bronski, M. Lehrman, J. Morris, T. Palazzi, S. Ramirez, and H. Touati. 2015. The Economics of Demand Flexibility. Boulder, CO: Rocky Mountain Institute.

EIA (U.S. Energy Information Administration). 2017. Average Price of Electricity to Ultimate Customers by End-Use Sector. Washington, DC: U.S. Energy Information Administration

Fares, R., and M. Webber. 2017. "The Impacts of Storing Solar Energy in the Home to Reduce Reliance on the Utility." Nature Energy 2: 17001.

Feldman, D., and T. Lowder. 2014. Banking on Solar: An Analysis of Banking Opportunities in the U.S. Distributed Photovoltaic Market. Golden, CO: National Renewable Energy Laboratory. NREL/TP-6A20-62605. 
Fitzgerald, G., J. Mandel, J, Morris, and H. Touati. 2015. The Economics of Battery Storage: How Multi-Use, Customer Sited Batteries Deliver the Most Services and Value to Customers on the Grid. Boulder, CO: Rocky Mountain Institute.

Hendron, B., J. Burch, and G. Barker. 2010. Tool for Generating Realistic Residential Hot Water Event Schedules. Golden, CO: National Renewable Energy Laboratory. NREL/CP-550-47685.

Khalilpour, K.R., and A. Vassallo. 2016. "Technoeconomic Parameter Analysis of PV-Battery Systems.” Renewable Energy 97: 757-768.

Luthander, R., J. Widén, D. Nilsson, and J. Palm. 2015. "Photovoltaic Self-Consumption in Buildings: A Review." Applied Energy 142: 80-94.

Manghani, R. 2014. The Future of Solar-Plus-Storage in the U.S. Boston: GTM Research.

Mathieu, J., M. Dyson, and D. Callaway. 2015. "Resource and Revenue Potential of California Residential Load Participation in Ancillary Services." Energy Policy 80: 76-87.

Parra, D., G. Walker, and M. Gillott. 2016. "Are Batteries the Optimum PV-Coupled Energy Storage for Dellings? Techno-Economic Comparison with Hot Water Tanks in the UK." Energy and Buildings 116: 614-621.

Salpakari, J., and P. Lund. 2016. "Optimal and Rule-Based Control Strategies for Energy Flexibility in Buildings with PV." Applied Energy 161: 425-436.

Simpkins, T., D. Cutler, K. Anderson, D. Olis, E. Elgqvist, M. Callahan, and A. Walker. 2014. REopt: A Platform for Energy System Integration and Optimization. Golden, CO: National Renewable Energy Laboratory. NREL/CP-7A40-61783.

Wilson, E., and S. Horowitz. 2016. 2016 Building America House Simulation Protocols Draft. Golden, CO: National Renewable Energy Laboratory. NREL/TP-5500-60988 